\title{
Seasonal variation of upwelling in the Alaskan Beaufort Sea: Impact of sea ice cover
}

\author{
Lena M. Schulze ${ }^{1}$ and Robert S. Pickart ${ }^{2}$ \\ Received 16 February 2012; revised 7 May 2012; accepted 8 May 2012; published 27 June 2012.
}

[1] Data from a mooring array deployed from August 2002 to September 2004 are used to characterize differences in upwelling near the shelf break in the Alaskan Beaufort Sea due to varying sea ice conditions. The record is divided into three ice seasons: open water, partial ice, and full ice. The basic response is the same in each of the seasons. Roughly $8 \mathrm{~h}$ after the onset of easterly winds the shelf break jet reverses, followed approximately $10 \mathrm{~h}$ later by upwelling of saltier water which is cold near the shelf break (Pacific Winter Water) and warm at depth (Atlantic Water). The secondary circulation at the outer shelf is, to first order, consistent with a two-dimensional Ekman balance of offshore flow in the upper layer and onshore flow at depth. There are, however, important seasonal differences in the upwelling. Overall the response is strongest in the partial ice season and weakest in the full ice season. It is believed that these differences are dictated by the degree to which wind stress is transmitted through the pack-ice, as the strength of the wind-forcing was comparable over the three seasons. An EOF-based upwelling index is constructed using information about the primary flow, secondary flow, and hydrography. The ability to predict upwelling using the wind record alone is explored, which demonstrates that $90 \%$ of easterly wind events exceeding $9.5 \mathrm{~m} \mathrm{~s}^{-1}$ drive significant upwelling. During certain periods the ice cover on the shelf became landfast, which altered the upwelling and circulation patterns near the shelf break.

Citation: Schulze, L. M., and R. S. Pickart (2012), Seasonal variation of upwelling in the Alaskan Beaufort Sea: Impact of sea ice cover, J. Geophys. Res., 117, C06022, doi:10.1029/2012JC007985.

\section{Introduction}

[2] It has long been known that upwelling takes place in the western Arctic Ocean along the edges of the Chukchi and Beaufort Seas [e.g., Mountain et al., 1976; Aagaard and Roach, 1990; Carmack and Kulikov, 1998]. Much of the early investigation focused on upwelling in canyons-in particular Barrow Canyon and Mackenzie Canyon - where the signals are particularly pronounced. For example, Bourke and Paquette [1976] demonstrated that water from the Atlantic layer in the southern Canada Basin can be upwelled onto the Chukchi shelf beyond the head of Barrow Canyon. It has been argued that the canyon upwelling is driven by a combination of factors, including local winds [e.g., Carmack and Kulikov, 1998], meridional gradients in sea level pressure [Mountain et al., 1976], and remotely generated shelfedge waves [e.g., Aagaard and Roach, 1990]. Recently, more attention has been paid to upwelling away from canyons, in particular along the shelf break of the Beaufort Sea

\footnotetext{
${ }^{1}$ School of Environmental Sciences, University of East Anglia, Norwich, UK. USA.

${ }^{2}$ Woods Hole Oceanographic Institution, Woods Hole, Massachusetts,

Corresponding author: L. M. Schulze, Vor dem Hagenn 55, D-38446 Wolfsburg, Germany. (1schulze@whoi.edu)

(C)2012. American Geophysical Union. All Rights Reserved. 0148-0227/12/2012JC007985
}

[Nikolopoulos et al., 2009; Pickart et al., 2009a, 2011]. This is driven by a combination of remote Pacific-born low pressure systems [Pickart et al., 2009b] and fluctuations of the Beaufort High [e.g., Watanabe, 2011; Mathis et al., 2012].

[3] The impacts of wind-driven shelf-basin exchange in this region of the Arctic are numerous and pronounced. The northward Ekman transport driven by easterly winds is a major source of freshwater to the Beaufort Gyre [Yang, 2006], which is the largest freshwater reservoir in the Arctic [Proshutinsky et al., 2009]. In summer and early fall such Ekman transport also fluxes heat offshore [Pickart et al., 2010]. Recent studies have concluded that lateral ocean heat flux from the shelf to the basin melts a substantial amount of ice in the marginal ice zone of the Pacific Arctic [Shimada et al., 2006; Zhang et al., 2008; Watanabe and Hasumi, 2009; Steele et al., 2010]. Wind-driven transport may contribute substantially to this. At the same time, the subsurface waters that are upwelled supply salt, nutrients, zooplankton, and other properties to the shelves. Using two years of mooring data in Barrow Canyon, Pickart and Fratantoni [2011] found that the majority of upwelling events fluxed nutrient-rich Pacific Winter Water from the upper halocline in the basin onto the Chukchi shelf, which may be one of the reasons why the northeast Chukchi Sea is so highly productive [Hill and Cota, 2005] and also rich in benthic biomass [Grebmeier et al., 2006]. In the Beaufort Sea, upwelling events can flux as much salt onto the shelf as the brine produced by polynya events, and the shoreward 


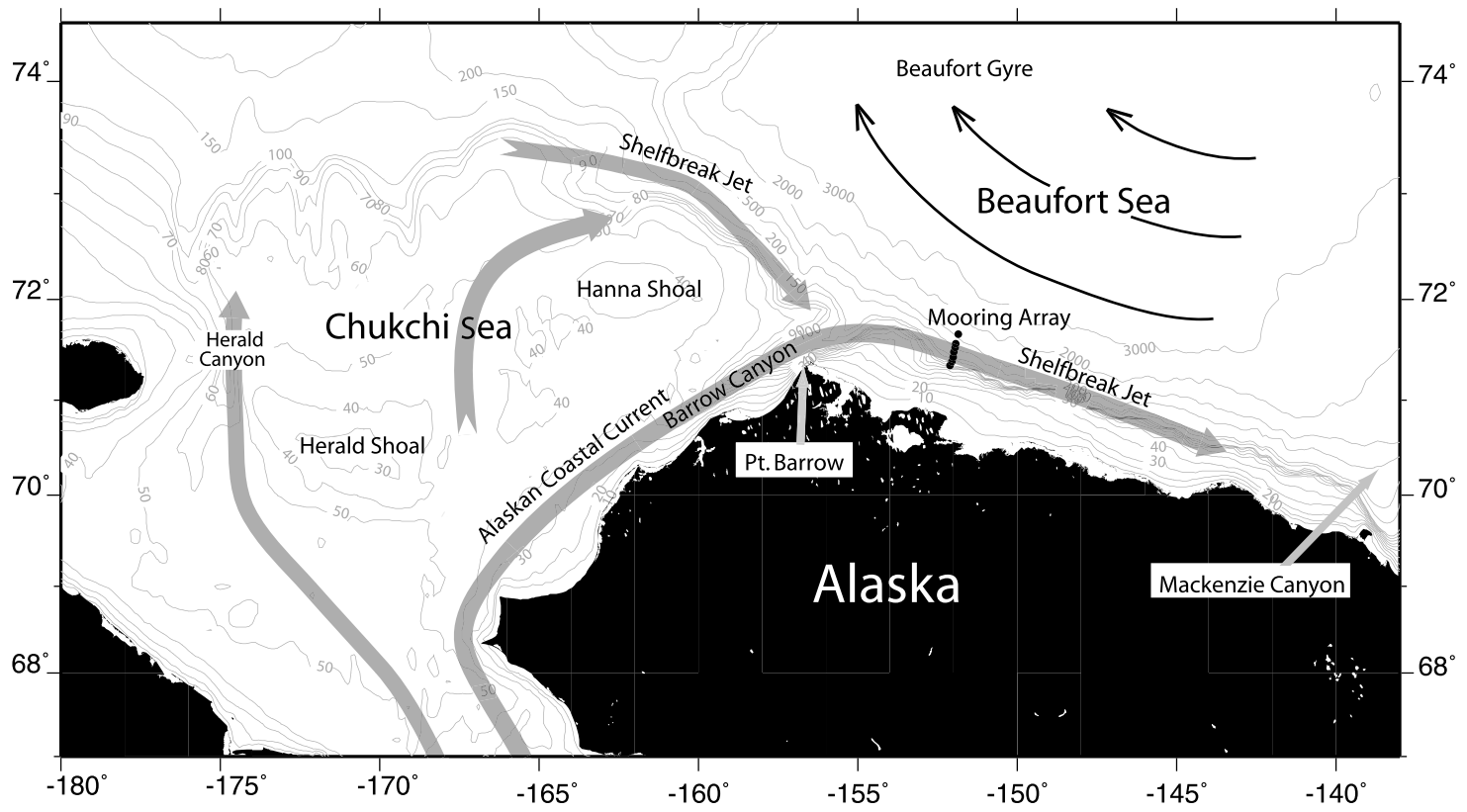

Figure 1. Major currents of the Chukchi and Beaufort Seas and geographical place names [after Spall et al., 2008]. The dots indicate the location of the SBI mooring array. The weather station is located at Pt. Barrow.

flux of zooplankton appears to impact the feeding of gray whales [Pickart et al., 2010]. In autumn 2011 a week-long upwelling event released as much $\mathrm{CO}_{2}$ to the atmosphere as the total annual sink of $\mathrm{CO}_{2}$ in the Beaufort Sea due to primary production [Mathis et al., 2012].

[4] Despite the importance of upwelling in the western Arctic to the hydrography of the water column, the pack-ice distribution, and various components of the ecosystem, much remains to be learned about the nature and driving of these events. This includes the character and magnitude of the cross-stream exchange, the impacts due to differing storm characteristics, and the role of sea ice. Pickart et al. [2009a] demonstrated that upwelling can occur even with a $100 \%$ ice cover, hence all seasons of the year need to be considered. One of the important factors to be considered during upwelling in the Chukchi and Beaufort Seas is the presence of the shelf break jet. In the absence of winds a narrow current flows eastward transporting Pacific-origin water toward the Canadian Arctic Archipelago. Under enhanced easterly winds the current reverses and can flow as fast as $1 \mathrm{~m} \mathrm{~s}^{-1}$ to the west. This strongly alters the parcel trajectories [Pickart et al., 2012] and consequently impacts the fate of the Pacific water in the Arctic [Watanabe, 2011]. For example, the water is more apt to be diverted into the transpolar drift under such conditions. As the climate warms, it is predicted that the number of high-latitude storms will increase and strengthen in intensity [Zhang et al., 2004; Sorteberg and Walsh, 2008], hence upwelling may become even more pronounced in this region of the Arctic Ocean.

[5] This paper uses two years of hydrographic and velocity data from a mooring array across the Beaufort shelf break and slope at $152^{\circ} \mathrm{W}$ to characterize the seasonal trends in upwelling, with particular focus on the role of sea ice. During the measurement period, from August 2002 to September 2004, 45 significant upwelling events occurred over conditions ranging from open water to $100 \%$ pack-ice. This has allowed us to characterize the oceanic response in terms of ice cover, which in turn will help us better understand how the system might respond to a stormier Arctic Ocean with less sea ice.

\section{Data and Methods}

\subsection{Mooring Array and Wind Data}

[6] The inflow of Pacific Water through Bering Strait splits into three main branches (Figure 1) which, upon reaching the northern edge of the Chukchi Sea, form a narrow shelf break jet [Nikolopoulos et al., 2009; Mathis et al., 2007]. To the east of Barrow Canyon the current is referred to as the Beaufort shelf break jet or the western Arctic boundary current and, under weak wind-forcing, consists of a narrow core (order $10-15 \mathrm{~km}$ wide) flowing eastward with an average speed of $15-20 \mathrm{~cm} \mathrm{~s}^{-1}$. During the late fall and winter the current often develops a deep "tail" extending down to about $250 \mathrm{~m}$ [Nikolopoulos et al., 2009] which arises during the relaxation phase of easterly wind events [Pickart et al., 2011]. Below the Pacific Water core of the current is the warm and salty Atlantic layer that gets upwelled during storm events [Nikolopoulos et al., 2009, Pickart et al., 2009a].

[7] In late-August 2002 a mooring array was deployed across the Beaufort shelf break and slope near $152^{\circ} \mathrm{W}$ for a time period of two years (with a short turnaround in September 2003) as part of the western Arctic Shelf-Basin Interactions (SBI) experiment. The array consisted of 8 moorings spanning a distance of $40 \mathrm{~km}$ between the 50 $1400 \mathrm{~m}$ isobaths (Figure 2). The horizontal spacing of the moorings was 4-6 km, except for the two offshore sites which were separated by $11 \mathrm{~km}$. All of the moorings were equipped with a conductivity/temperature/depth (CTD) profiler. At the inner six moorings (BS1-BS6) upward-facing acoustic Doppler current profilers (ADCPs) were used to 


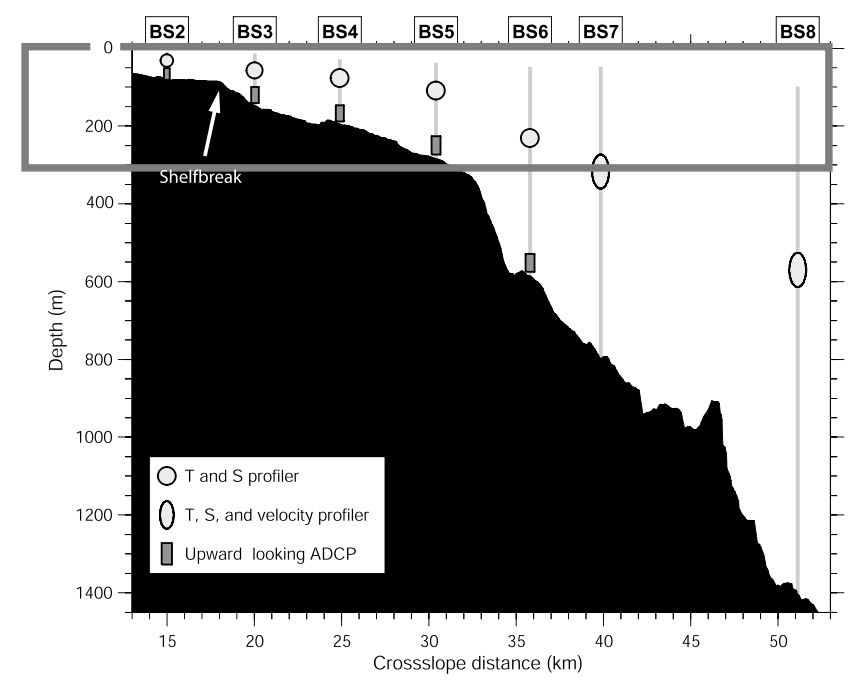

Figure 2. Configuration of the SBI mooring array [after Spall et al., 2008]. The location and name of each mooring is marked at the top and the instruments used are listed in the key. The gray box indicates the portion of the water column considered in this study.

measure velocity, while the CTD profilers at the outer two moorings (BS7 and BS8) were equipped with acoustic traveltime current meters. The velocity data from BS7 and BS8 are not considered in this study. Also, the inshore-most mooring BS1 did not return velocity data for the first year and hence is not included in the analysis. The CTD data are limited to the part of the water column below $40-50 \mathrm{~m}$ due to the potential of damage to the instruments from ridging ice at depths shallower than this. The ADCP velocity profiles have a blanking region near the surface that ranges from $8 \mathrm{~m}$ at BS2 to $45 \mathrm{~m}$ at BS6.

[8] The CTD profilers provided four vertical traces of hydrographic data per day, while the ADCPs measured velocities every hour. The reader is referred to Fratantoni et al. [2006] and Spall et al. [2008] for a discussion of the measurement accuracies for temperature, salinity, and velocity. The overall data return was very good [see Nikolopoulos et al., 2009]. The main exception was at mooring BS3 which did not return velocity data shallower than $55 \mathrm{~m}$ during the second deployment year. This data gap was filled using Laplacian-spline interpolation. A large part of the present analysis was carried out using the set of vertical hydrographic sections (potential temperature, salinity, potential density) and velocity sections (along-stream, crossstream) used in previous studies. The methodology employed in the construction of these sections is given in Spall et al. [2008] and Nikolopoulos et al. [2009]. For the previous studies as well as the present analysis, in the absence of strong winds the along-stream velocity was rotated to $125^{\circ} \mathrm{T}$, which is approximately aligned with the topography of the continental slope to the west of the array (i.e., upstream of the array). The cross-stream velocity direction is $35^{\circ} \mathrm{T}$, with positive flow directed offshore. For the present study we consider only the upper $300 \mathrm{~m}$ of the water column.

[9] The wind data used in this study are from the meteorological station at Pt. Barrow, AK located roughly $150 \mathrm{~km}$ to the west of the mooring array. The data were rotated to be aligned with the coast such that the along-coast direction is orientated along 105 T [Nikolopoulos et al., 2009]. Previous studies have demonstrated that the winds at Pt. Barrow are generally a good proxy for those at the mooring array [Nikolopoulos et al., 2009; Pickart et al., 2011].

\subsection{Ice Concentration and Ice Velocity}

[10] A time series of ice concentration for the region of the mooring array was constructed using data from the passive radiometer on the Advanced Microwave Scanning Radiometer-Earth Observing System (AMSR-E). The resolution of the sensors is $12.5 \mathrm{~km}$ and the accuracy of the constructed daily images of ice concentration is generally $10 \%$ [Spreen et al., 2008]. The data were interpolated onto a $6.25 \mathrm{~km}$ grid and the concentration averaged within a $35 \mathrm{~km}$ (zonal) by $55 \mathrm{~km}$ (meridional) box around the mooring array [see also Pickart et al., 2009a]. The resulting time series is shown in Figure 3. A record of ice velocity was constructed using data from the upward-facing $\mathrm{ADCP}$ at mooring $\mathrm{BS} 2$ (bottom depth of $81 \mathrm{~m}$ on the outer shelf). For a description of the technique employed, the reader is referred to Pickart et al. [2009a]. The ice velocities were only accurate enough to be considered when the ice cover at the array exceeded 50\%.

\subsection{Landfast Ice Data}

[11] To identify the presence of landfast ice during the period of our analysis, we used the product constructed by Mahoney et al. [2007] for the region of the Alaskan Beaufort Sea. Mahoney et al. [2007] used Radarsat SAR data to identify the seaward extent of landfast ice along the Beaufort shelf from Pt. Barrow to the Mackenzie trough over an area $950 \mathrm{~km}$ long (zonal) by $330 \mathrm{~km}$ wide (meridional), for the 9-year time period 1996-2004. The SAR images spanned a period of 2-3 days and were used to construct a record between October and July with a temporal resolution of 10 days. Two criteria were used to identify landfast ice: the ice had to be contiguous with the coast and motionless for at least 20 days. Mahoney et al. [2007] calculated the acrossshelf width of the landfast ice at 200 locations along the coast in this region. Using the location closest to our mooring array, a time series of landfast ice width was constructed.

\subsection{Identifying Upwelling Events}

[12] An upwelling event was defined according to the following three criteria: (1) easterly wind speed at Pt. Barrow stronger than $4 \mathrm{~m} \mathrm{~s}^{-1}$, (2) significant reversed flow (generally exceeding $10 \mathrm{~cm} \mathrm{~s}^{-1}$ ) averaged over the upper $100 \mathrm{~m}$ of the water column, (3) salinity in the near-bottom layer (averaged over the bottom $50 \mathrm{~m}$ ) in the vicinity of the shelf break greater than the monthly mean. Similar criteria were used by Pickart et al. [2009a] to identify upwelling during the fall and winter of 2002-3. Temperature was not considered for identifying the events since it is not monotonic with depth. The wind criterion was chosen because, on average, easterly winds exceeding this magnitude can reverse the shelf break jet. However, as demonstrated below, wind alone is not sufficient to identify the events. In fact, due to the internal (un-forced) variability of the current, all three criteria were necessary to unequivocally identify the upwelling events. A time-varying salinity criterion was necessary in light of the seasonal variability of the water masses being advected by the jet. 


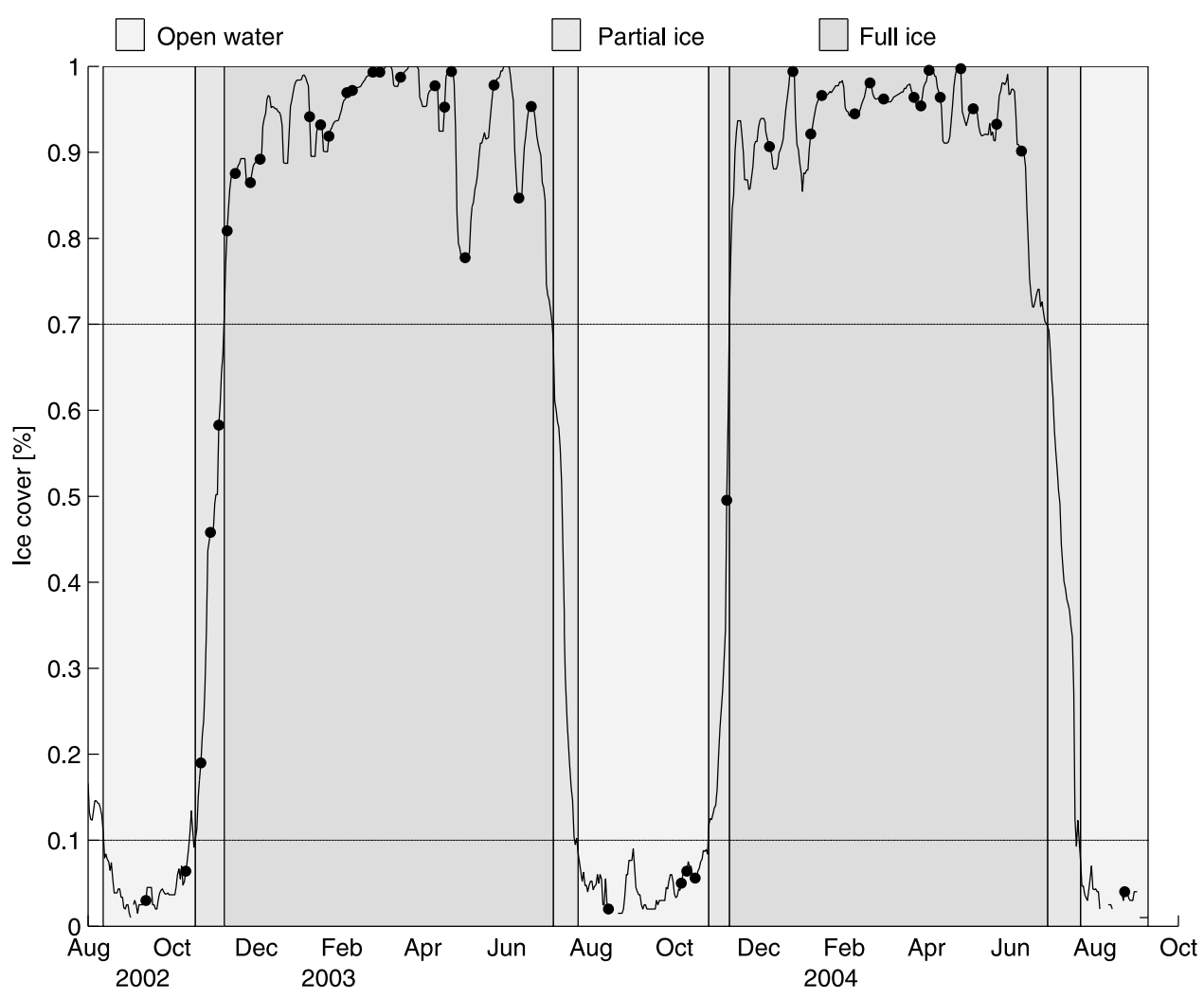

Figure 3. Percentage of ice cover in the vicinity of the array. Solid circles mark the upwelling events. The different shades of gray indicate the three ice seasons.

[13] Using the above criteria, 45 upwelling events were identified for the time period August 2002 to September 2004, with events occurring in all seasons. To put this in perspective, about $23 \%$ of the 24 -month period was subject to upwelling. The greatest density of events was found in November 2003 during which four events took place. The average wind-forcing associated with an event lasted $105 \mathrm{~h}$ (4.3 days). The velocity and salinity response of the water column lagged the wind by $8 \mathrm{~h}$ and $18 \mathrm{~h}$, respectively, and lasted an average of $74 \mathrm{~h}$ and $71 \mathrm{~h}$, respectively. We note that September 2003 contained strong upwelling favorable winds but only limited hydrographic data were available then due to the mooring turnaround, hence no events were identified during that month.

\subsection{Ice Seasons}

[14] Most of the Arctic is covered by ice for a majority of the year and ice concentration and thickness are two of the major factors influencing the dynamics of the circulation and air-sea interaction of the Arctic Ocean. Hence, rather than consider the four calendar seasons, we divided the year into three ice seasons: the open water season when ice concentration near the array was less than $10 \%$, the partial ice season when the concentration was between $10 \%$ and $70 \%$, and the full ice season when the ice cover exceeded $70 \%$. (The results presented below are not sensitive to small variations in these definitions.) We note that no events were found during the partial ice season in the spring and therefore this season only consists of the two relatively short periods during the fall. As seen in Figure 3, the full ice season is the longest of the three seasons and 34 of the upwelling events are found during that time, while only 4 and 7 events were identified during the partial ice and open water periods, respectively. This disparity in the number of events should be kept in mind when considering the results of the analysis below. During 8 of the full ice storms, landfast ice covered the inner part of the array. Consequently, this subset of storms is not considered in the full ice composite averages presented below; that is, the full ice composites refer to a complete ice cover that is still mobile. In section 3.5 we consider the set of landfast ice storms.

\subsection{Rotating the Velocities}

[15] Previous studies using the SBI mooring data have considered an along-stream/cross-stream coordinate system based on the principle axis ellipses of the flow, which is approximately aligned with the bathymetry to the west of the array [Nikolopoulos et al., 2009; Pickart et al., 2009a; von Appen and Pickart, 2012]. In particular, the positive alongstream direction was defined to be southeast along $125 \mathrm{~T}$. However, Pickart et al. [2011] found that this was not an appropriate choice of an along-stream angle for the particular storm event that they studied. They instead determined the rotation angle by computing a single mean vector averaged spatially over the array and temporally over the length of the storm. This choice of angle more clearly separated the primary circulation from the secondary circulation. Following this methodology, we determined the mean flow vector for each storm by averaging the velocity vertically over the upper $100 \mathrm{~m}$ and laterally over the five inshore moorings (BS2-BS6), for the duration of the event. Figure 4 demonstrates how different the average angle of flow can be from 

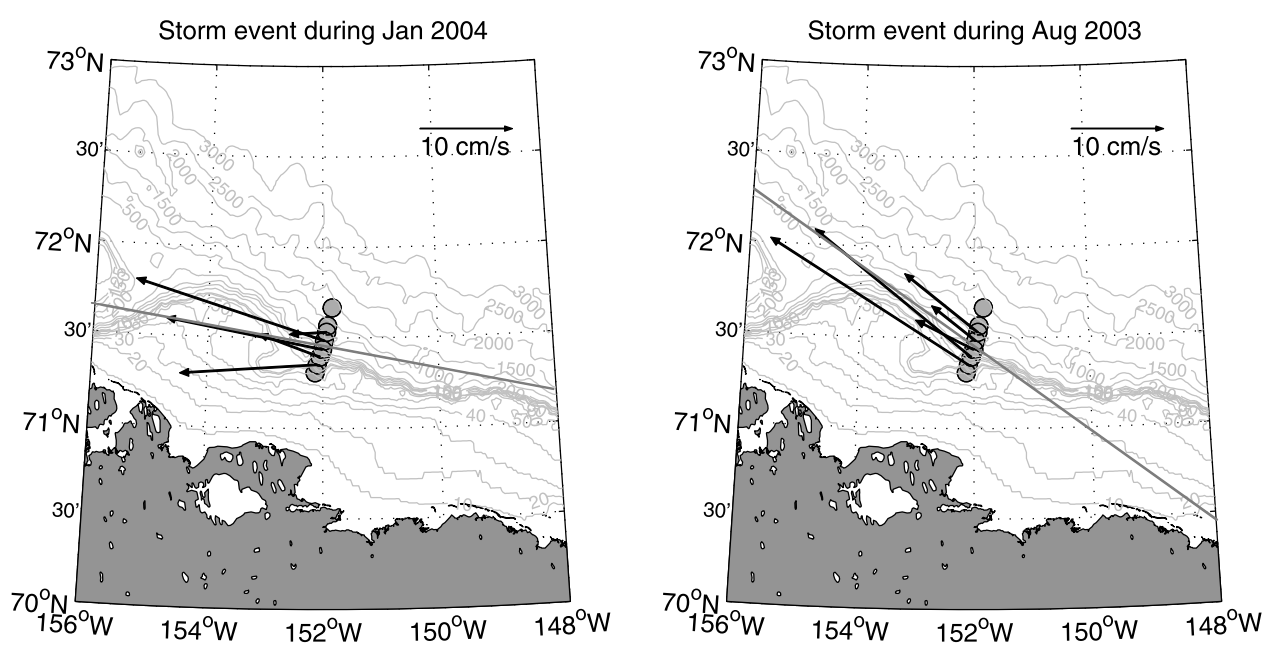

Figure 4. Flow response during two upwelling events. The circles mark the location of the moorings. The vectors denote the average flow over the upper $100 \mathrm{~m}$ for the length of each storm. The solid line marks the average flow direction during the storm.

event to event. The left-hand panel shows an event with an average flow speed of $13 \mathrm{~cm} \mathrm{~s}^{-1}$ directed at $-79^{\circ} \mathrm{T}$. Although the magnitude of the average velocity for the event shown in the right-hand panel is comparable at $14 \mathrm{~cm} \mathrm{~s}^{-1}$, the average angle of flow is $-54^{\circ} \mathrm{T}$, i.e., $25^{\circ}$ different. The overall mean angle for all 45 events is $-65^{\circ} \mathrm{T} \pm 11^{\circ} \mathrm{T}$, ranging between $-39^{\circ} \mathrm{T}$ and $-95^{\circ} \mathrm{T}$.

[16] After computing the angle for each storm, we rotated the velocities accordingly into the along-stream and crossstream components; in other words, we implemented a storm-dependent rotation angle. This proved to be crucial for elucidating the secondary circulation patterns. For example, in the majority of cases the cross-stream velocities at the edge of the shelf, rotated as such, displayed offshore flow in the upper layer and onshore flow in the lower layer, which was not readily apparent when using a single rotation angle for all of the storms. Hence, without such a varying rotation angle, the analysis of the secondary circulation did not produce straightforward, interpretable results. We note that, even when using a storm dependent rotation angle, three of the open water cases and three of the (mobile) full ice cases did not display an Ekman-type secondary circulation at the shelf break. There is no obvious reason or distinguishing characteristic that suggests anything special about these events. In any case, they are excluded from the analysis of secondary flow, but retained in the analysis of the hydrography.

[17] It is not entirely clear why the primary angle of the reversed flow varies from storm to storm. The most obvious reason would be the direction of the prevailing wind. However, the calculated flow angles for the events are not significantly correlated with the wind direction (or wind speed) measured at Pt. Barrow. While it may be that the wind direction in the vicinity of the array is consistently different than that at Pt. Barrow, we have no measurement of this (and a detailed analysis of atmospheric reanalysis fields is beyond the scope of this study). Another possible factor could be the state of the shelf break jet prior to the storm, but no correlation was found between the angle of the reversed flow and the strength of the eastward-flowing jet before the storm. Finally, there is a hint of seasonality in that the reversed flow is directed a bit more to the northeast during the full ice season. Unfortunately, however, we were not able to objectively quantify this because of the limited number of events.

\section{Ocean Response to Upwelling Favorable Winds}

[18] The main goal of this study is to describe the variation in the upwelling response along the Beaufort shelf break and slope associated with differences in sea ice cover. An effective way to address this is by computing composite vertical sections of various quantities. We begin by showing sections of along-stream velocity (where the along-stream direction varies from storm to storm as discussed above), salinity anomaly, and temperature anomaly. The anomalies are relative to the undisturbed state of the system for the given ice season. As mentioned above, we consider only the upper $300 \mathrm{~m}$ of the domain. For all sections the reader is looking to the west, with positive along-stream velocities directed to the east.

[19] A typical upwelling event along the Beaufort slope and shelf is caused by easterly winds exceeding roughly $6 \mathrm{~m} \mathrm{~s}^{-1}$. After an average time lag of $8 \mathrm{~h}$ the flow in the upper $300 \mathrm{~m}$ reverses to the west, followed approximately $10 \mathrm{~h}$ later by the occurrence of upwelling. This is characterized by an uptilt of isohalines and isopycnals toward the shelf, accompanied by seaward-directed flow in the upper layer and shoreward-directed flow at depth in the vicinity of the shelf break.

\subsection{Ice-Season Composites}

[20] Before presenting the composite averages during upwelling, we describe the circulation and hydrography of the Beaufort shelf and slope in the absence of easterly winds. The undisturbed state of the shelf break jet is quite different for the three ice seasons (Figures $5 \mathrm{a}-5 \mathrm{c}$ ). In the open water season the jet is surface-intensified, while in the other two seasons it is strongest near the bottom (in the full ice case the surface layer is flowing to the west, likely in response to the background easterly winds during winter). While von Appen and Pickart [2012] identified two different 

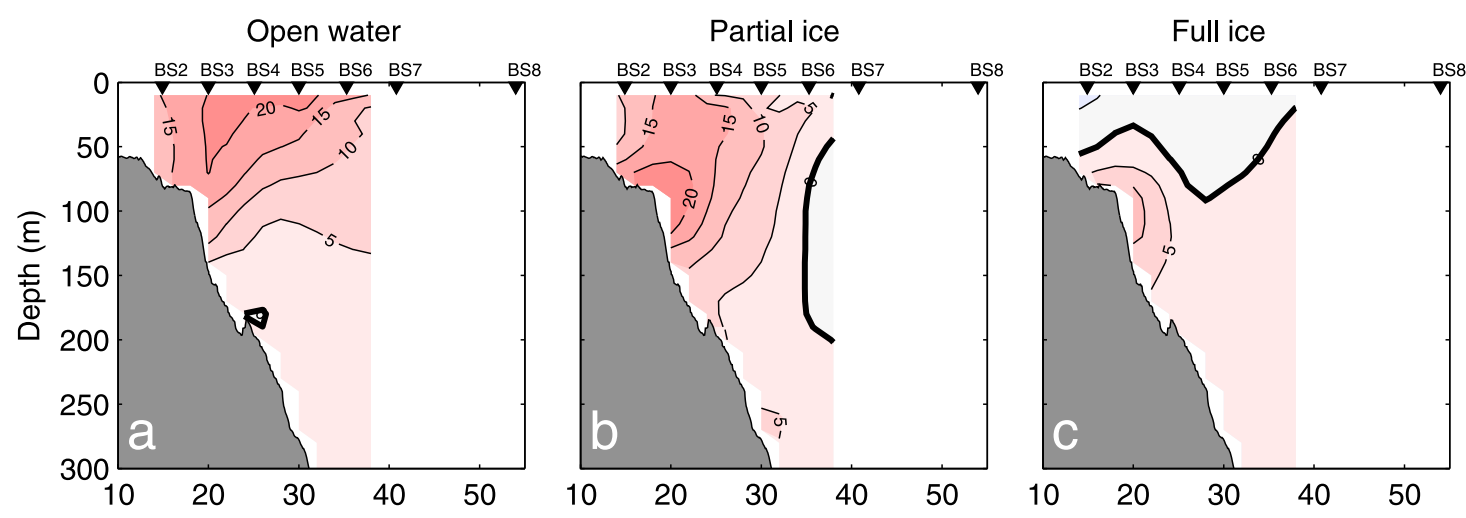

\section{Alongstream velocity $[\mathrm{cm} / \mathrm{s}]$}
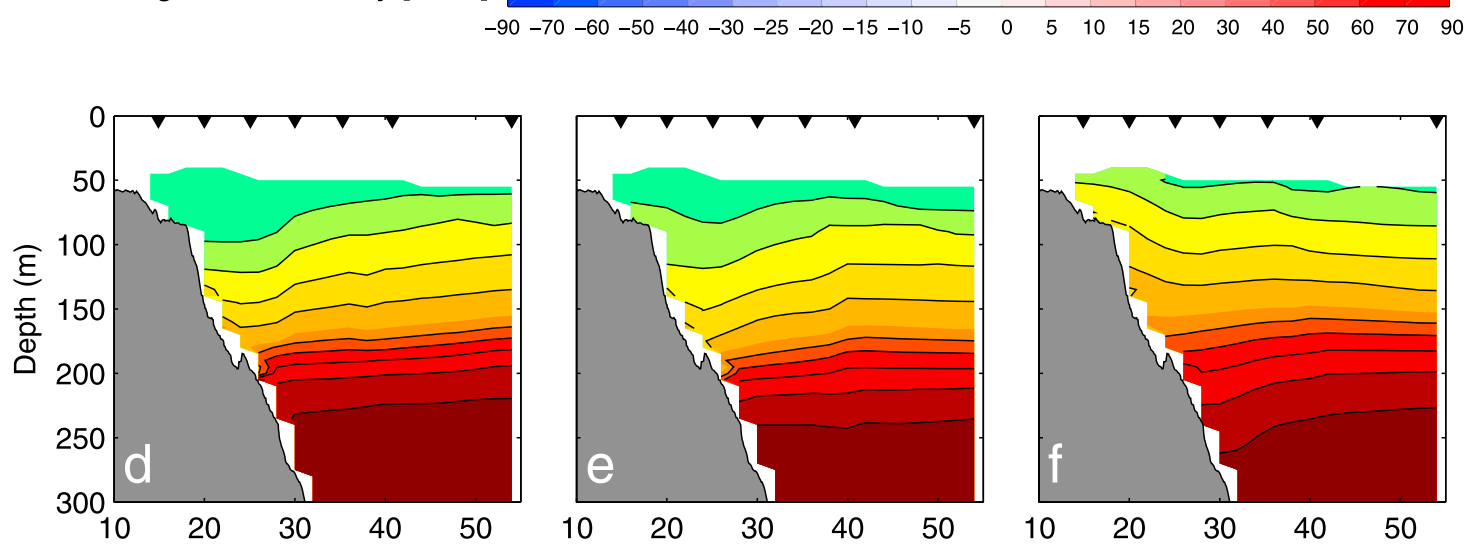

Salinity

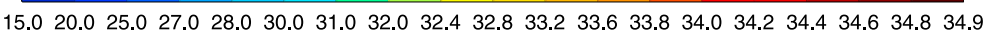
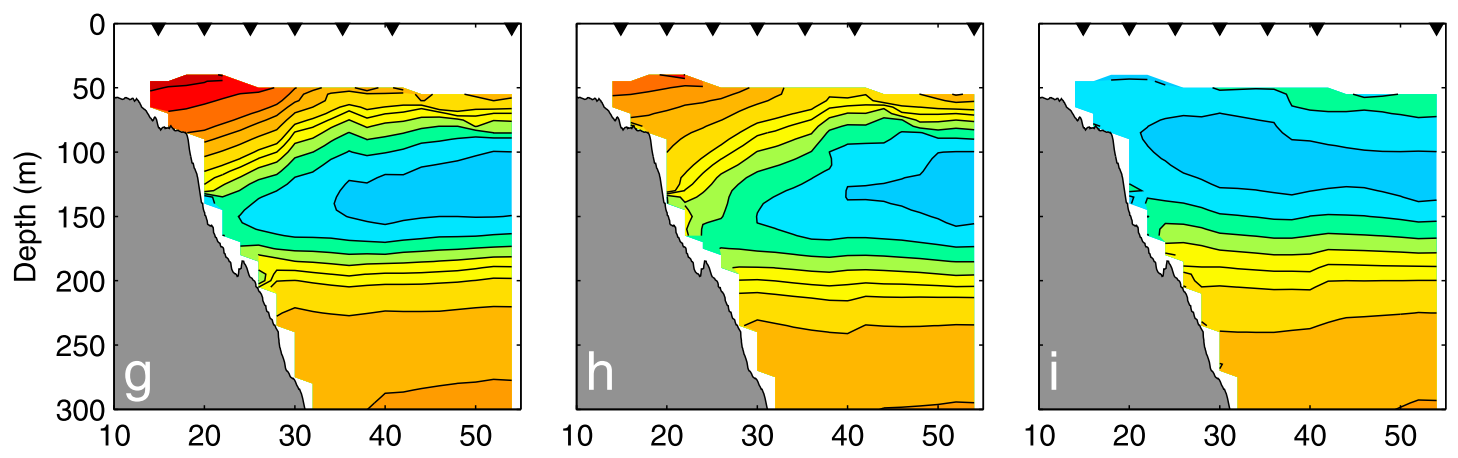

\section{Temperature $\left[{ }^{\circ} \mathrm{C}\right]$}

$-1.90-1.75-1.70-1.65-1.60-1.40-1.20-1.00-0.80-0.400 .00 \quad 0.50 \quad 1.00 \quad 2.00 \quad 3.00 \quad 5.00 \quad 7.00$

Figure 5. Composite vertical sections of the undisturbed states of the water column during each ice season: $(\mathrm{a}-\mathrm{c})$ along-stream velocity, $(\mathrm{d}-\mathrm{f})$ salinity, $(\mathrm{g}-\mathrm{i})$ potential temperature.

summer configurations of the undisturbed jet - one surfaceintensified and the other bottom-intensified - the latter tends to be present in the transition from spring to summer and then again from summer to fall; hence, it does not show up in the open water undisturbed composite presented here. There are also differences between the partial and full ice undisturbed jet composites displayed in Figures $5 \mathrm{~b}$ and $5 \mathrm{c}$ and the calendar means presented in Nikolopoulos et al. [2009]. In that study the deep extension of the shelf break jet appears in the fall/winter composite, but, as explained above, this deep eastward flow forms immediately after major upwelling events as the winds subside, hence it is not part of the undisturbed flow.

[21] The undisturbed salinity and temperature fields also vary seasonally (Figures 5d-5i). During the open water period there is warm and fresh Alaskan Coastal Water present on the shoreward side of the domain being advected by the surface-intensified shelf break jet (this water mass also 

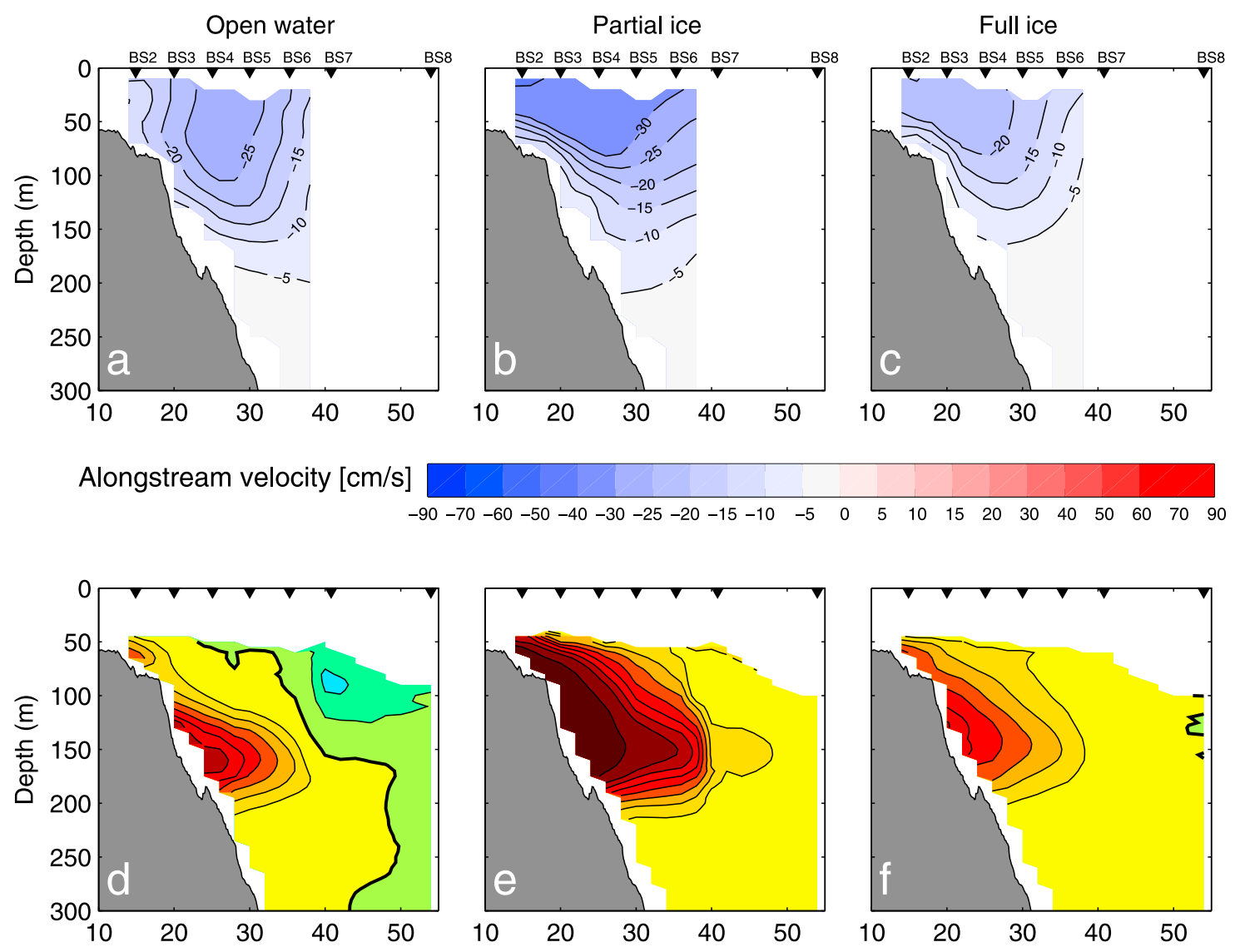

Salinity anomaly
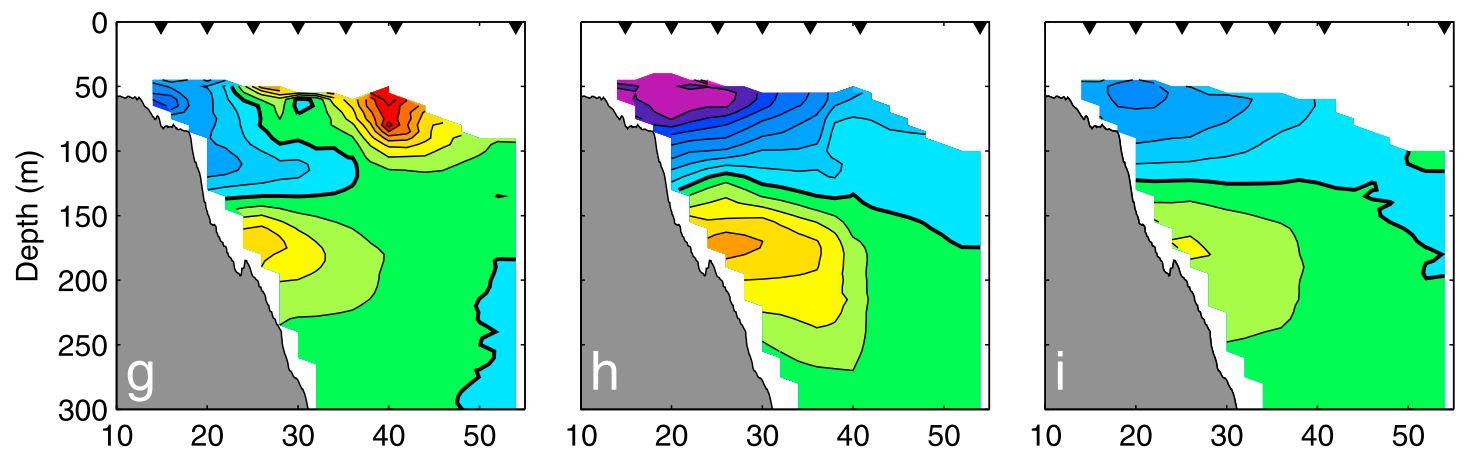

Temperature anomaly $\left[{ }^{\circ} \mathrm{C}\right]$

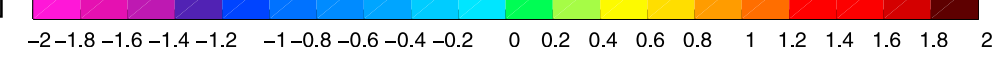

Figure 6. Composite vertical sections for storm events during each ice season: (a-c) along-stream velocity, (d-f) salinity, (g-i) potential temperature.

has a presence during the partial ice season). By contrast, there is no Alaska Coastal Water present in the upper layer during the time period of full ice cover. As discussed in Nikolopoulos et al. [2009], Pacific Winter Water is present along the Beaufort slope throughout the year, situated above the warm and salty Atlantic layer, though it is most pronounced when there is full ice cover. This is mainly due to the outflow of winter water from the Chukchi shelf that passes by the array in mid- to late-spring [Spall et al., 2008].
[22] In each of the ice seasons the easterly winds are strong enough to reverse the shelf break jet throughout the upper $300 \mathrm{~m}$ (Figures 6a-6c) and over the entire array (BS2-BS6). The reversed flow is surface-intensified and strongest toward the coast for the partial and full ice seasons, while the core of the westward flow is located offshore during the open water season. This may be due to the fact that the undisturbed jet is surface-intensified near the shelf break in the open water season (Figure 5a). Consistent with Pickart et al. [2009a], 

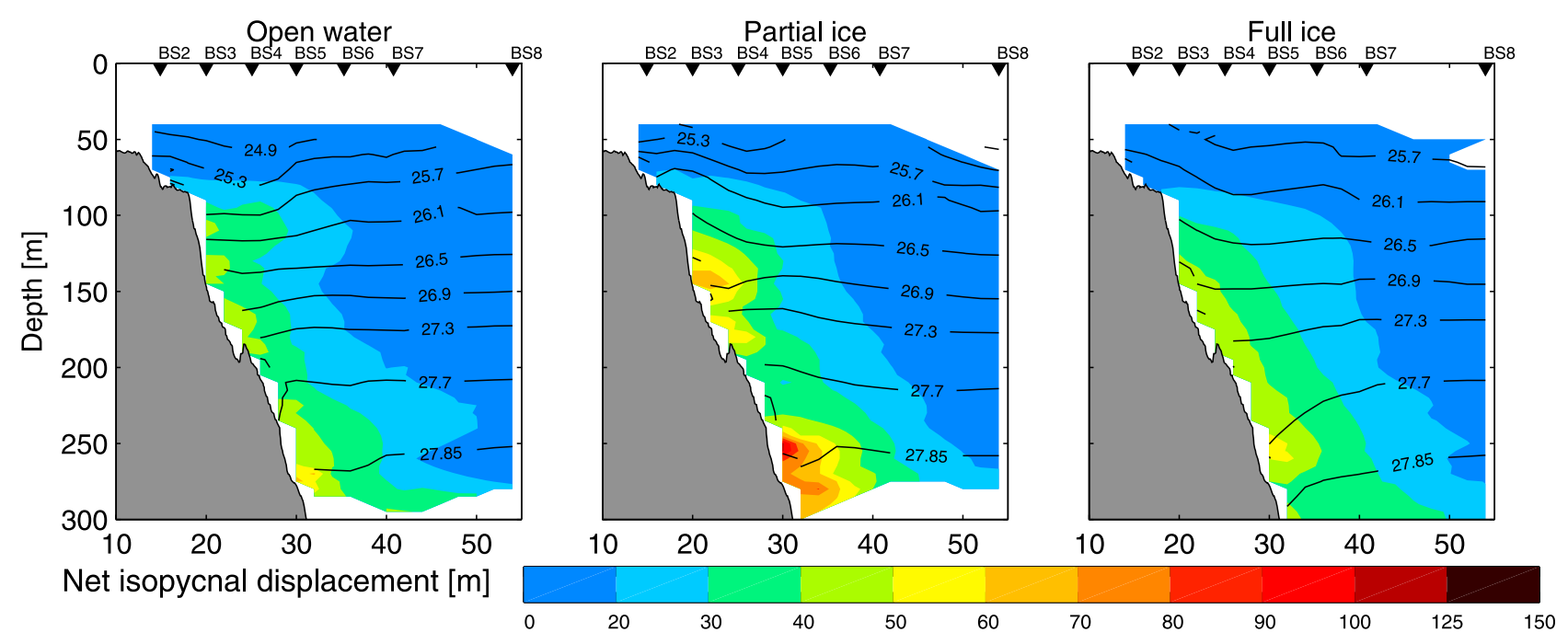

Figure 7. Same as Figure 6 but for net isopycnal displacement.

the velocity reversal is weakest during the full ice season (when the ice concentration can be $100 \%$ ). Interestingly, the reversed flow is strongest during the partial ice season as opposed to the open water season (this is true for the velocity anomalies as well, not shown). This is likely due to the ice-ocean drag which is very effective at transmitting stress from the wind to the ocean when the ice keels are freely moving [Pite et al., 1995]. During a subsequent deployment of mooring BS3 (in the center of the boundary current) from 2005 to 2006, an upward-looking sonar was deployed which regularly measured keel depths in the range of 15-30 m. In the Canadian Beaufort Sea, Williams et al. [2006] found similar enhanced upwelling in the presence of partial ice cover. In contrast, with a full ice cover the internal ice stresses are apt to limit the transfer of stress to the water column, which would explain the weakened flow reversals observed during that season (Figure 6c). It is important to note that the differences in flow reversals documented in Figure 6 are not a function of storm strength: the meteorological data from Pt. Barrow indicate that, on average, both the magnitude and direction of the prevailing winds during storm events were comparable for the different ice seasons throughout the SBI period.

[23] During the occurrence of upwelling, large positive salinity anomalies are observed adjacent to the shelf break (Figures 6d-6f). As was the case with the along-stream velocity, the strongest response occurs during the partial ice season with values exceeding 1.2 from the shelf break to a depth of roughly $200 \mathrm{~m}$. Again the signal is weakest during the full ice season, although it is not that dissimilar to the open water case. Magnitudes reach up to 0.6 in both cases, but the area over which this value occurs is smaller in the full ice season. There are also differences in the depth of the maximum salinity anomaly. It is shallowest during the partial ice season $(120 \mathrm{~m})$ and deeper during the other two seasons (140 m during the full ice season and $160 \mathrm{~m}$ when there is open water).

[24] The temperature structure during upwelling is more complex, though generally comparable for all three seasons (Figures 6g-6i). In each case there is cooling near the shelf break and upper slope (due to displaced Pacific Winter Water), and warming along the mid slope below a depth of about $150 \mathrm{~m}$ (due to displaced Atlantic Water). This dipole is asymmetric in that the cooling is about $40-60$ percent larger than the warming. Again the signal is strongest during the partial ice season (Figure 6h). Although not apparent in the composites, during 12 of the individual events the upwelling was strong enough to briefly bring warm and salty Atlantic water all the way onto the shelf. The November storm investigated by Pickart et al. [2011] was one of these cases. However, as was true in Barrow Canyon [Pickart and Fratantoni, 2011], the majority of events transported predominantly Pacific Winter Water onto the shelf. Another notable seasonal difference is the presence of anomalously warm water seaward of the shelf in the upper layer during open water events. This is likely due to offshore advection of warm Alaskan Coastal Water that is present in the shelf break jet during this time of year (Figure 5g) [see also von Appen and Pickart, 2012]. A comparable signal is seen in the open water salinity anomaly as well.

[25] Another metric of upwelling that is of interest is the isopycnal displacement during the storms. This was calculated as follows. We chose 11 isopycnal surfaces spanning the upper $300 \mathrm{~m}$ in the undisturbed state and tracked their locations at each horizontal grid point during all of the events. The maximum vertical displacements during the storm, in relation to their initial positions, were then tabulated and used to create composite vertical sections for each of the ice seasons (Figure 7). One should keep in mind when viewing these composites that the upwelling process is not two-dimensional, and water parcels are being advected from the east as well as upslope. As expected, the largest isopycnal displacements occurred during the partial ice season. There are two separate maxima, one near $250 \mathrm{~m}$ associated with the 27.85 isopycnal, and one near $150 \mathrm{~m}$ close to the 26.9 isopycnal. The former is displaced $80 \mathrm{~m}$ upwards and the latter $60 \mathrm{~m}$. Presently it is unclear why there are two regions of enhanced displacement, but this occurs regularly (it is evident in the open water composite as well). As mentioned above, there were instances when Atlantic Water 

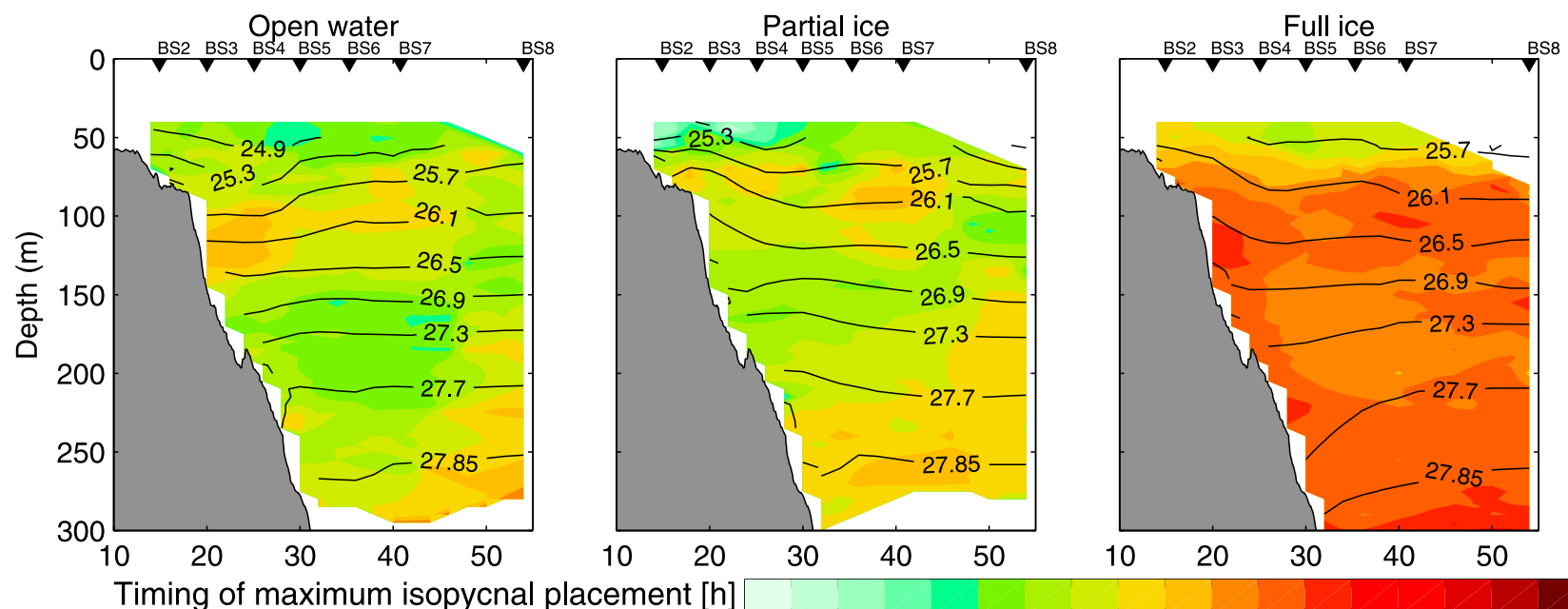

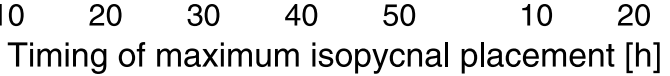

$\begin{array}{lllllllllllllllllll}0 & 12 & 24 & 30 & 36 & 42 & 48 & 54 & 60 & 66 & 72 & 78 & 84 & 90 & 96 & 102 & 108 & 114 & 120\end{array}$

Figure 8. Same as Figure 6 but for elapsed time for the maximum isopycnal displacement to be reached.

was upwelled onto the shelf, and, during the strongest event, water as deep as $350 \mathrm{~m}$ was transported onto the shelf. This is significantly larger than the value reported by Williams et al. [2006] who deduced that upwelling occurred from depths of $200 \mathrm{~m}$ in the Canadian Beaufort Sea.

[26] In Figure 7 one sees that the isopycnal displacement under full ice cover was comparable to that in open water. This may seem at odds with the differences in flow reversals seen in Figure 6 between these two seasons. However, while the strength of the winds and their direction are similar for the different ice seasons, the storms lasted an average of $24 \mathrm{~h}$ longer during the full ice season (4 days versus 3 days). Thus, one might expect a correspondingly increased isopycnal displacement during the full ice season. This is consistent with the calculated time periods of isopycnal displacement. Figure 8 shows the composite vertical sections of the elapsed time it took for the maximum isopycnal displacements to be reached during the storms. While this time period is similar in the open water and partial ice cases, one sees that it is roughly $24 \mathrm{~h}$ longer for the full ice case. Figure 8 also reveals that the displacement of isopycnals occurs nearly simultaneously throughout the domain.

[27] Using the maximum isopycnal displacements and their timing, we calculated average upwelling rates (Figure 9). The corresponding upwelling rates during the open water and partial ice seasons are as large as $20-30 \mathrm{~m} \mathrm{day}^{-1}$. By way of comparison, upwelling rates near the shelf break of the Middle Atlantic Bight are estimated to be around $10 \mathrm{~m} \mathrm{day}^{-1}$ [Barth et al., 1998; Pickart, 2000], although the upwelling reported there is due to bottom boundary layer processes not associated with wind (we are unaware of any windforced upwelling estimates in that region). Of course the rates presented in Figure 9 are average values for all of the storms composited over the given season. We also calculated "instantaneous" upwelling rates during each of the storms by tabulating isopycnal displacements between adjacent time steps. This revealed synoptic values as large as 90 $150 \mathrm{~m} \mathrm{day}^{-1}$ during the open water and partial ice seasons, demonstrating that isopycnals can be displaced relatively great distances within a few hours.
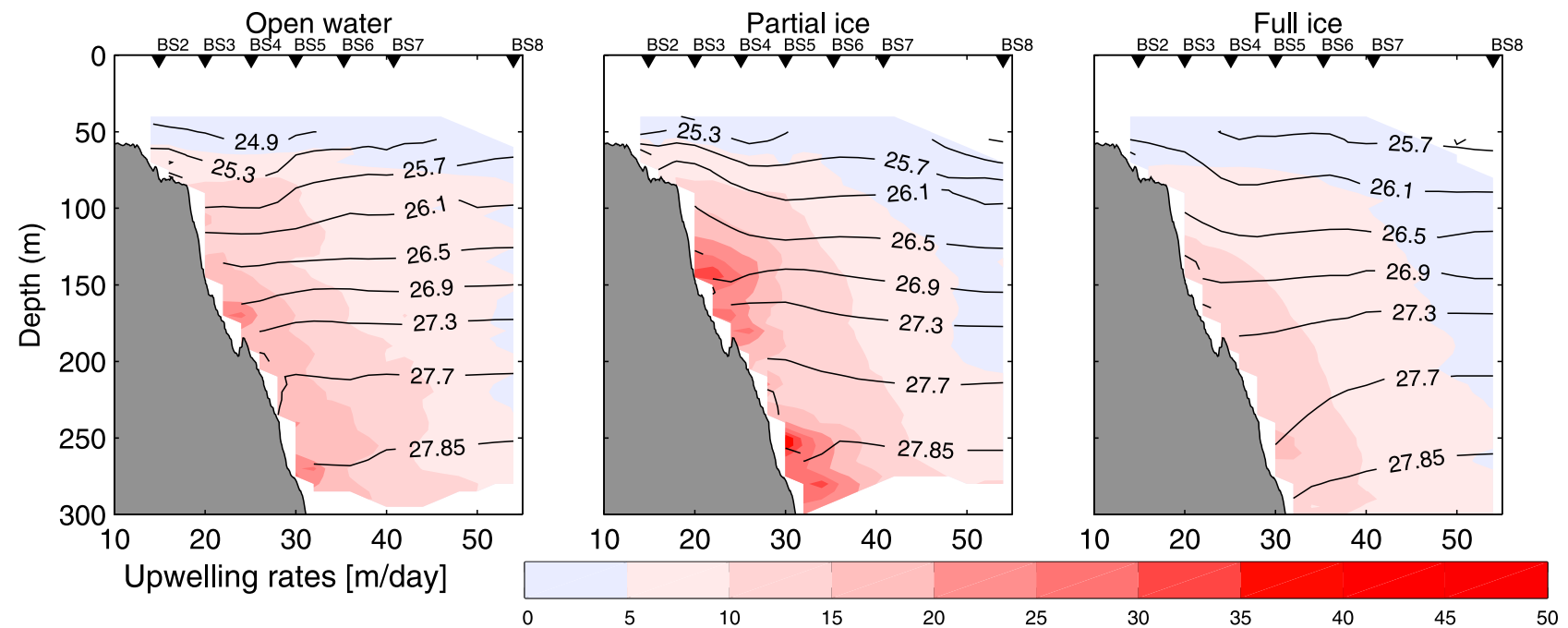

Figure 9. Same as Figure 6 but for upwelling rates. 


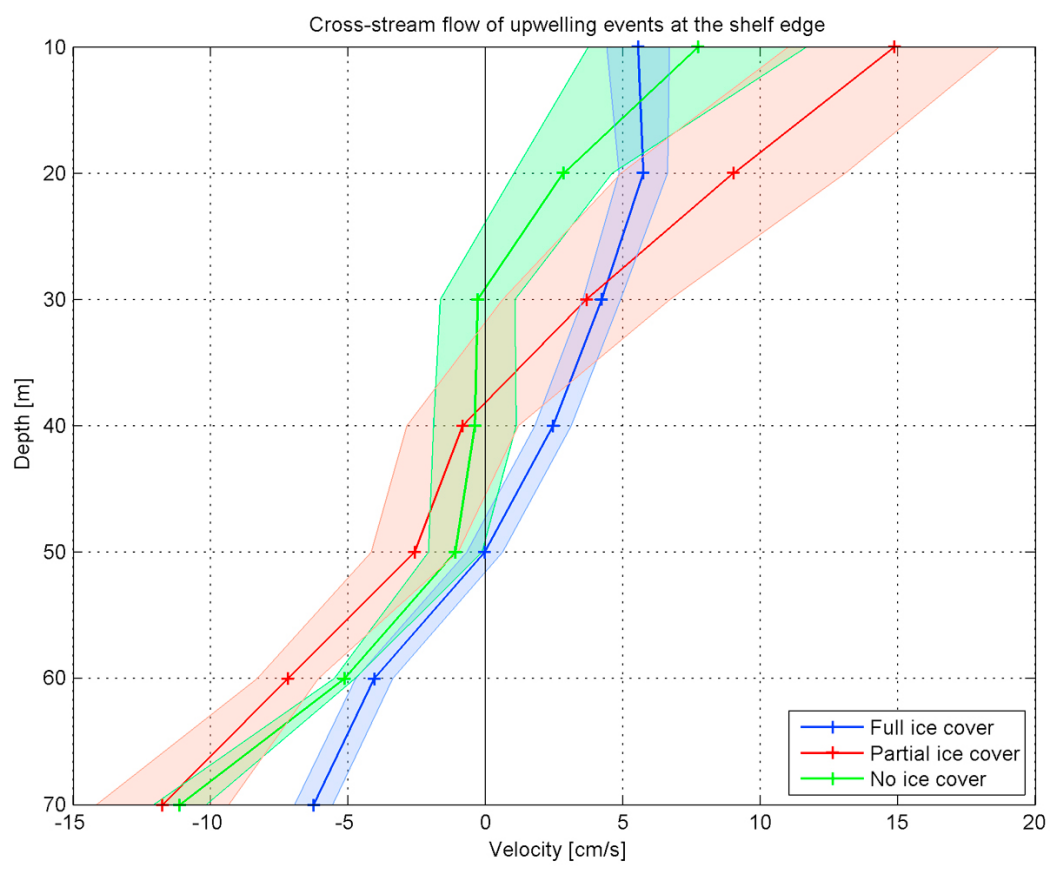

Figure 10. Composite cross-stream velocity profiles at the edge of the shelf (mooring BS2) for storm events during each ice season. Shading denotes the standard errors.

\subsection{Secondary Circulation}

[28] Due to the enhanced easterly winds associated with the storms, we would expect there to be an offshore-directed Ekman transport in the surface layer. As discussed above (Section 2.6), after objectively rotating the velocities into an along-stream/cross-stream coordinate system for each storm, this offshore transport became apparent. However, only at the mooring closest to the shelf edge (BS2) was there a persistent onshore return flow at depth. This is consistent with the results of Pickart et al. [2011] who analyzed a single storm and demonstrated that, seaward of the shelf break, the flow response was not two dimensional. Furthermore, although there was generally offshore flow in the upper layer and onshore flow at depth in the vicinity of the shelf edge, the details of this secondary flow pattern varied from event to event. In order to objectively determine the depth of the flow reversal at BS2, which we take here to be the Ekman depth, we averaged the depth of the zero velocity contour over the duration of each event (this also served to reduce some of the noise in the secondary flow measurement). As noted earlier, three of the open water events and three of the full ice events did not show this offshore/onshore baroclinic flow structure and, as such, are excluded from our analysis of the secondary circulation. (The 8 landfast events are considered separately below in section 3.5.) The average Ekman depth of the remaining 31 events is $46.2 \mathrm{~m} \pm 8.7 \mathrm{~m}$ (note that the depth of the water column at BS2 is $81 \mathrm{~m}$ ).

[29] The ice season composites of the secondary flow at the shelf edge show some interesting features (Figure 10). Most evident is the fact that the cross-stream circulation is strongest in the partial ice season, consistent with the primary flow response described above (Figures 6a-6c). During the other two seasons, open water and full ice, the secondary flow is weaker and more comparable. There is also the suggestion that the Ekman depth deepens when there is ice cover present (however the error bars are considerable for the open water season and partial ice season). It is worthwhile as well to consider the storm-to-storm variability in the secondary flow. This was done using the varying Ekman depths to compute the vertically averaged onshore and offshore velocity for each event at mooring BS2. The resulting time series (Figure 11) indicates that the two velocities tend to balance each other - that is, there is little net flow on or off the shelf during upwelling events. To be specific, the mean offshore and onshore velocity over all of the storms is identical $\left(6.7 \mathrm{~cm} \mathrm{~s}^{-1}\right)$, while the RMS difference between the two is $0.71 \mathrm{~cm} \mathrm{~s}^{-1}$. This approximate two-dimensional balance at the shelf edge was found as well by Pickart et al. [2011] in their detailed study of a single storm event. Note that such a mass balance does not imply a zero net property flux [Pickart et al., 2010].

[30] Are the observed offshore velocities consistent with Ekman theory? To address this we computed the predicted Ekman transport for each storm, $\mathrm{T}_{\mathrm{E}}=\tau /(\rho f)$, where $\tau$ is the average wind stress during the event (in the direction of the mean wind over all of the storms) computed from the Pt. Barrow meteorological data following Large and Pond [1981], $\rho$ is the average density of the water column at mooring BS2, and $f$ is the Coriolis parameter $(1.38 \times$ $\left.10^{-4} \mathrm{~s}^{-1}\right)$. We assume an along-stream length scale of $500 \mathrm{~km}$ for the storms, which is also the length of the Alaskan Beaufort shelf (from Pt. Barrow to $141^{\circ} \mathrm{W}$ ). To do a precise comparison with the observations, several things would have to be considered. First, we would need to calculate the volume transport orthogonal to the direction of the wind, but this direction is unknown except at Pt. Barrow (which is located $150 \mathrm{~km}$ to the west of the array). As noted above, the angle of the wind measured at Pt. Barrow for each storm is not significantly correlated with the along-stream angle of the 


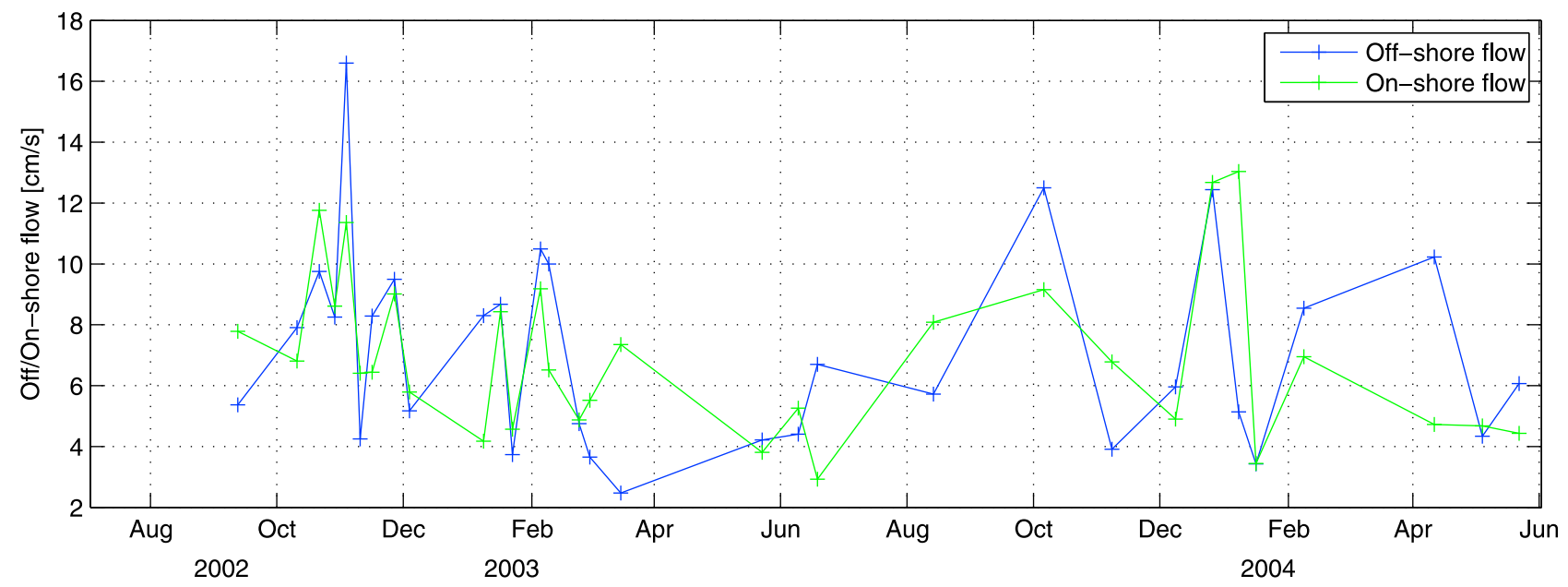

Figure 11. Average offshore and onshore flow during the storm events at the edge of the shelf (see text for details).

reversed flow. Second, as mentioned above, the transmission of surface stress to the water column is impacted by the presence of ice. In particular, the stress should be larger during the partial ice season (due to the freely moving ice keels), and smaller during the full ice season (due to internal ice stresses). However, it is beyond the scope of this study to address these considerations.

[31] Despite these caveats, there is reasonable agreement between the calculated offshore transport and the predicted Ekman transport (Figure 12). Overall, the predicted Ekman flux is about $40 \%$ smaller than the observed offshore transport. This might be due in part to the uncertainty in the wind direction at the array site noted above. In any event, Figure 12 demonstrates that, to first order, the off-shelf transport during the storms is consistent with Ekman theory. In the mean, the measured offshore flux is $1.3 \mathrm{~Sv}$, with a range of $0.2-3.3 \mathrm{~Sv}$. For an average storm response of 3 days, this suggests that it could take as few as $4-5$ storms to flush the entire Alaskan Beaufort shelf.

\subsection{Upwelling Index}

[32] As detailed above, the water column responds in a variety of ways to the onset of easterly winds along the Beaufort shelf break and slope. It is thus desirable to come up with a single measure of the magnitude of the upwelling. We use an empirical orthogonal function (EOF) approach to do so. In the most basic sense, the easterly winds cause a strong reversal in the upper layer of the boundary current, an increase in near-bottom salinity, and a secondary circulation pattern of off-shelf flow in the upper layer and on-shelf flow at depth, which to first order represents a balanced Ekman cell. The relevant in situ time series are shown in Figure 13, together with the time series of along-coast wind-forcing, for the entire two year period. The along-stream velocity is an average over the upper $200 \mathrm{~m}$ in the vicinity of the shelf break (between moorings BS2 and BS4). Outside of the upwelling events we used the rotation angle of $125^{\circ} \mathrm{T}$ employed by Nikolopoulos et al. [2009]. The salinity was obtained by averaging over the bottom $50 \mathrm{~m}$ of the water

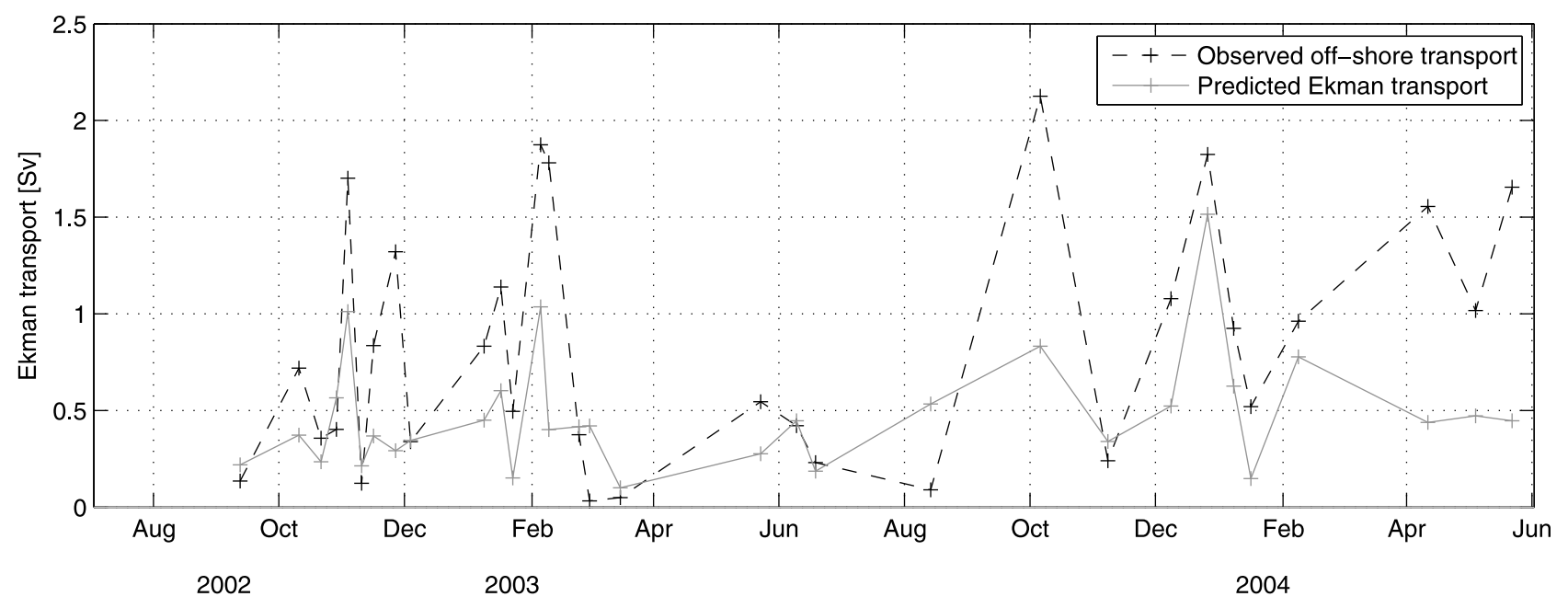

Figure 12. Calculated offshore transport versus predicted Ekman transport during the storm events at the edge of the shelf (see text for details). 

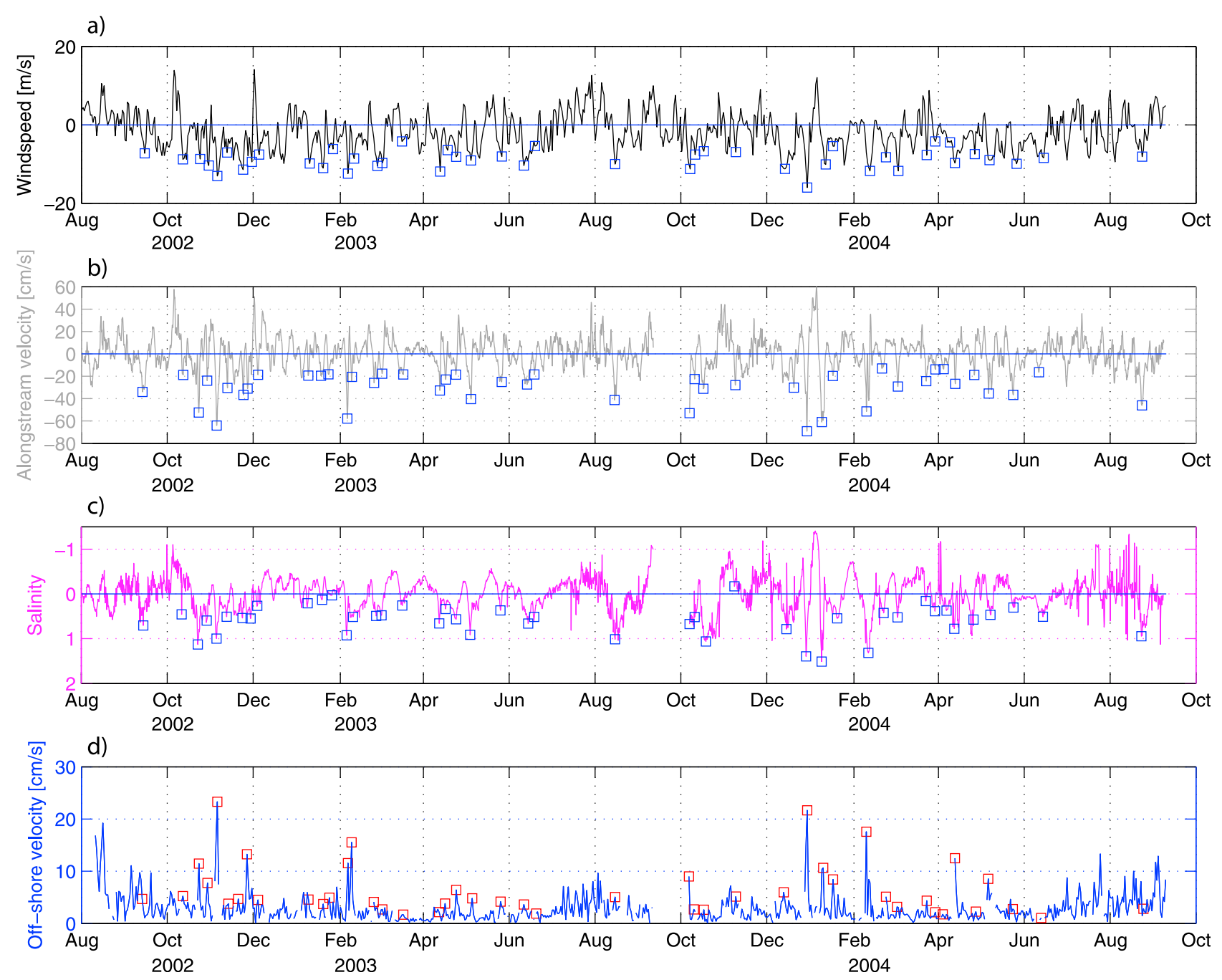

Figure 13. Time series of (a) along-coast wind speed measured at Pt. Barrow, (b) high-passed alongstream velocity in the vicinity of the shelf break, (c) high-passed salinity in the bottom $50 \mathrm{~m}$ near the shelf break, and (d) offshore velocity in the upper layer at the edge of the shelf. Squares in each time series mark the upwelling events.

column near the shelf edge. Both of these time series were high-passed with a 5-day filter to minimize longer-term variability outside of the storms, which was especially pronounced for salinity (e.g., the seasonal signal). In light of the statistical relationships noted above, the velocity time series was adjusted forward by $8 \mathrm{~h}$ and the salinity time series forward by $18 \mathrm{~h}$ to align these variables with the wind [see also Pickart et al., 2009a]. The gap in the mooring records corresponds to the turnaround of the array.

[33] It is apparent in Figure 13 that the peak along-stream velocities coincide with peaks in wind speed. The squares, marking the observed upwelling events in each record, show that most of the positive salinity anomalies also correspond to the wind events and observed upwelling, although some significant peaks cannot be explained by upwelling. To obtain time series of off- and onshore flow, we averaged the positive cross-stream velocity in the upper layer and the negative flow in the bottom layer at mooring BS2. This was done using the overall average Ekman depth of $45 \mathrm{~m}$ to delineate the two layers for the entire record. The resulting off- and onshore velocity time series show less correlation with the other time series. While each upwelling event has a well-defined peak in along-stream velocity and salinity, this is not always the case for the cross-stream flow. This suggests that other variability is present in the secondary circulation. Nevertheless, there is generally a clear signal in cross-stream velocity associated with the upwelling events.

[34] Using the time series of along-stream velocity, salinity, offshore flow, and onshore return flow, we calculated the EOFs. We note, however, that during the summer time period there was a significant amount of variance in the salinity due to the intermittent presence of warm and fresh Alaskan Coastal Water. Hence, we removed two periods from our calculation - five weeks during Jul-Aug 2003 and seven weeks during Jun-Aug 2004. No upwelling was observed during either of these periods. (The gap in Sep-Oct 2003 is the mooring turnaround.) The resulting first EOF mode (Figure 14) is taken to be the upwelling index. The mode explains $44 \%$ of the observed variance, and it is clear that the upwelling events (circles) correspond to peaks in the modal 


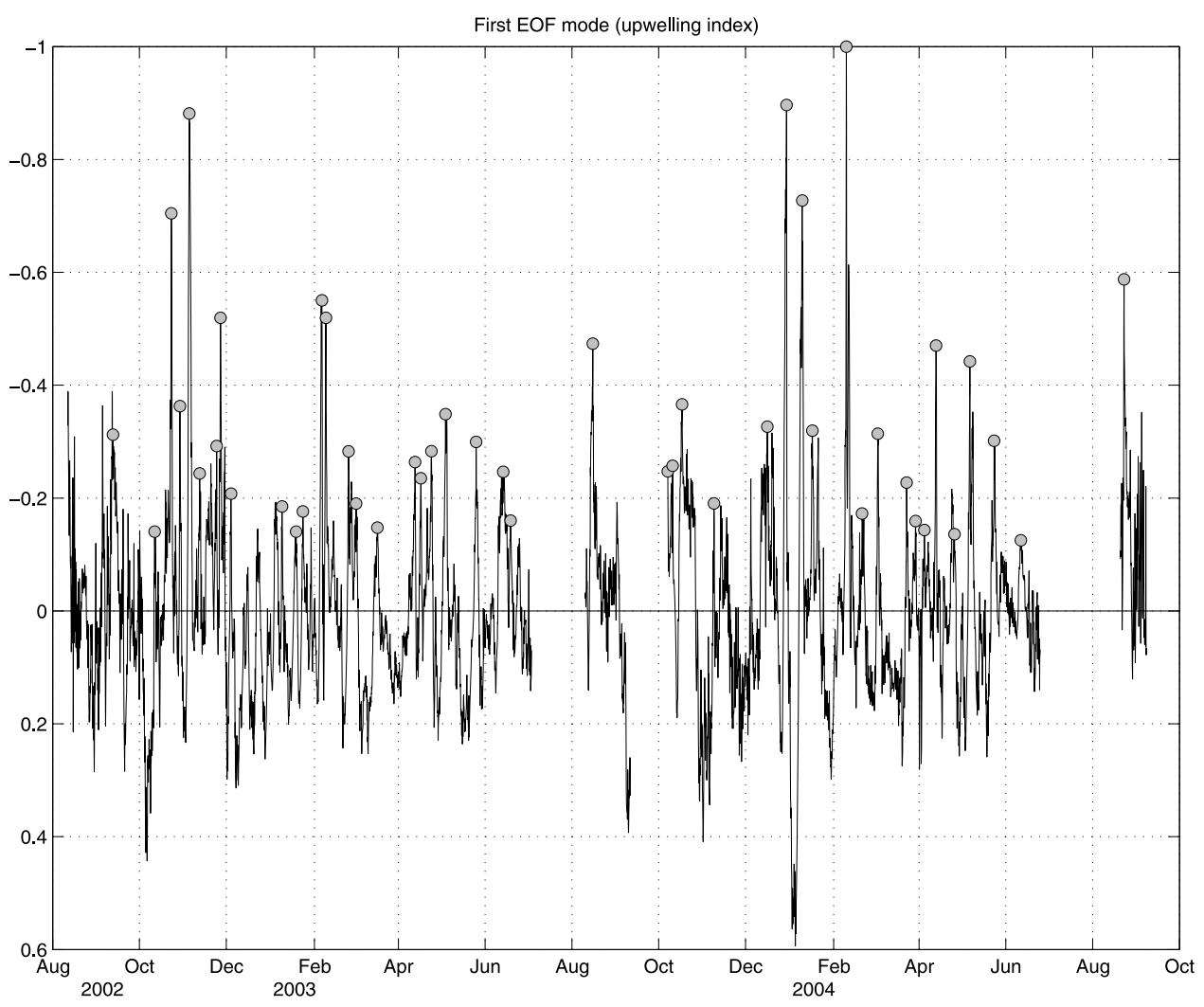

Figure 14. EOF mode 1 for the velocity, salinity, offshore and onshore velocity time series, referred to in the text as the upwelling index. Circles indicate the upwelling events. The gaps in the time series are explained in the text.

time series. Using only along-stream velocity and salinity, Pickart et al. [2009a] calculated a similar EOF mode accounting for $70 \%$ of the variance for the four-month period Oct 2002 to Jan 2003. The smaller percentage of variance explained here is mainly due to the noisy signal of the crossstream flow noted above. If we exclude the secondary circulation from our calculation the percentage of the dominant EOF increases to $80 \%$ for the two-year record. Also, if we compute separate EOFs for the different ice seasons, the percent variance explained by the dominant mode is comparable in each case.

[35] One sees in Figure 14 that the EOF has a significant number peaks that do not correspond to upwelling events. In the beginning of record (August to early October, 2002) this is due to the fact that the Alaskan Coastal Water was periodically flowing past the array (we did not remove this portion of the record from the EOF since it contained two upwelling events). There are also 17 peaks during the twoyear period that corresponded to wind events that reversed the shelf break jet but did not lead to significant upwelling; these could be considered marginal upwelling events. When these are discounted, along with the Alaskan Coastal Water occurrences, it leaves 10 peaks in the EOF time series that are unexplained. Inspection of these events indicates that they were associated with the passage of eddies or other mesoscale features. Overall then, for the two-year period under consideration, our objectively determined index was effective approximately $85 \%$ of the time for identifying upwelling events (both strong and weak).
[36] By comparing the reconstructed time series from the EOF with the original input time series, we can determine which of the four input variables contributes most to the EOF. Not surprisingly, the noisier time series of crossstream flow had the least impact, particularly the onshore flow, while the along-stream velocity and salinity influenced the EOF to a comparable degree. Accordingly, we re-did the EOF calculation without the onshore flow. Although the resulting dominant mode explained a greater percentage of the variance $(59 \%$ versus $44 \%$ ), the effectiveness of the EOF as an upwelling index was in fact degraded. In particular, the number of peaks not corresponding to definitive upwelling events increased. The likely explanation for this is that the added constraint of onshore flow (even though imperfect) isolates wind-driven upwelling events more effectively due to the Ekman response of compensating offshore and onshore flow. Hence, the most robust upwelling index requires a measure of the secondary circulation.

\subsection{Predicting the Upwelling Response}

[37] It is of interest to further quantify the relationship between the wind-forcing and ocean response in order to provide a predictive capability for upwelling in this part of the Arctic Ocean. We do this first by computing transfer functions [e.g., Beardsley et al., 1985]. In particular, we divide the yearlong records of wind speed, along-stream velocity, and salinity into the three ice seasons and perform the corresponding linear regressions (all quantities were significantly correlated with each other for each of the ice 
Table 1. Transfer Functions of Along-Stream Velocity and Salinity Versus Wind Speed and Related Metrics

\begin{tabular}{|c|c|c|c|}
\hline & Open Water & Partial Ice & Full Ice \\
\hline Transfer coefficient for along-stream velocity - wind speed $\left(\mathrm{cm} \mathrm{s}^{-1} / \mathrm{m} \mathrm{s}^{-1}\right)$ & $2.28 \pm 0.26$ & $2.92 \pm 0.43$ & $1.75 \pm 0.35$ \\
\hline Transfer coefficient for salinity - wind speed $\left(1 / \mathrm{m} \mathrm{s}^{-1}\right)$ & $-0.042 \pm 0.015$ & $-0.051 \pm 0.018$ & $-0.042 \pm 0.031$ \\
\hline Velocity of shelf break jet in absence of wind-forcing & $11.17 \mathrm{~cm} \mathrm{~s}^{-1}$ & $11.32 \mathrm{~cm} \mathrm{~s}^{-1}$ & $6.63 \mathrm{~cm} \mathrm{~s}^{-1}$ \\
\hline Wind needed to reverse the shelf break jet & $-5 \mathrm{~m} \mathrm{~s}^{-1}$ & $-3.9 \mathrm{~m} \mathrm{~s}^{-1}$ & $-3.7 \mathrm{~m} \mathrm{~s}^{-1}$ \\
\hline Change in salinity for average storm $\left(6 \mathrm{~m} \mathrm{~s}^{-1}\right)$ & 0.269 & 0.318 & 0.266 \\
\hline
\end{tabular}

seasons). Table 1 shows the corresponding transfer coefficients for the three different ice seasons. The value of the coefficient is a measure of how much the variable in question will change for a unit change in wind. The y-intercept for the regression of along-stream velocity versus wind speed represents the strength of the shelf break jet in the absence of wind-forcing, while the $\mathrm{x}$-intercept indicates the wind strength needed to reverse the current. One sees that it takes more wind to reverse the current in open water than it does when there is partial ice present, even though the undisturbed jet in the two states is comparable. This is consistent with the above results and discussion regarding the increased efficiency of freely moving ice keels to impart stress to the water column. Note also that it takes approximately the same amount of wind to reverse the jet whether there is partial ice cover or full ice cover, even though internal ice stresses likely absorb some of the wind stress in the latter case. This is due to the weaker shelf break jet when the ice cover is complete. The same calculation for near-bottom salinity versus wind speed quantifies the varying degrees of upwelling for a comparable wind in each ice season. One again sees that salinity changes the most during the partial ice season.
[38] To get an overall assessment of the sensitivity of the Beaufort slope to wind-forced upwelling, we compared the number of easterly wind bursts measured at Pt. Barrow (where a burst had to be at least $30 \mathrm{~h}$ in duration) to those events that were in fact associated with upwelling (45 events total). In particular, we tabulated all of the easterly wind peaks in Figure 13a (exceeding $4 \mathrm{~m} \mathrm{~s}^{-1}$ ) along with the upwelling events identified by the objective approach described in Section 2.4 (denoted by the squares in Figure 13a) as a function of the wind speed of the event. This information is presented in Figure 15. One sees that only $65-70 \%$ of the wind events that exceeded the threshold of $4-7 \mathrm{~m} \mathrm{~s}^{-1}$ result in significant upwelling. However, there is a sharp transition in this percentage such that, once the wind exceeds $9.5 \mathrm{~m} \mathrm{~s}^{-1}$, greater than $90 \%$ of the wind events drive upwelling (note that this is for a sample size of approximately 20 events). Once the wind reaches $11 \mathrm{~m} \mathrm{~s}^{-1}, 100 \%$ of the storms result in upwelling (sample size of 10 storms). The analogous calculation was done for the different ice seasons. Not surprisingly, the $100 \%$ threshold was reached more quickly (i.e., for weaker wind speed) in the partial ice and

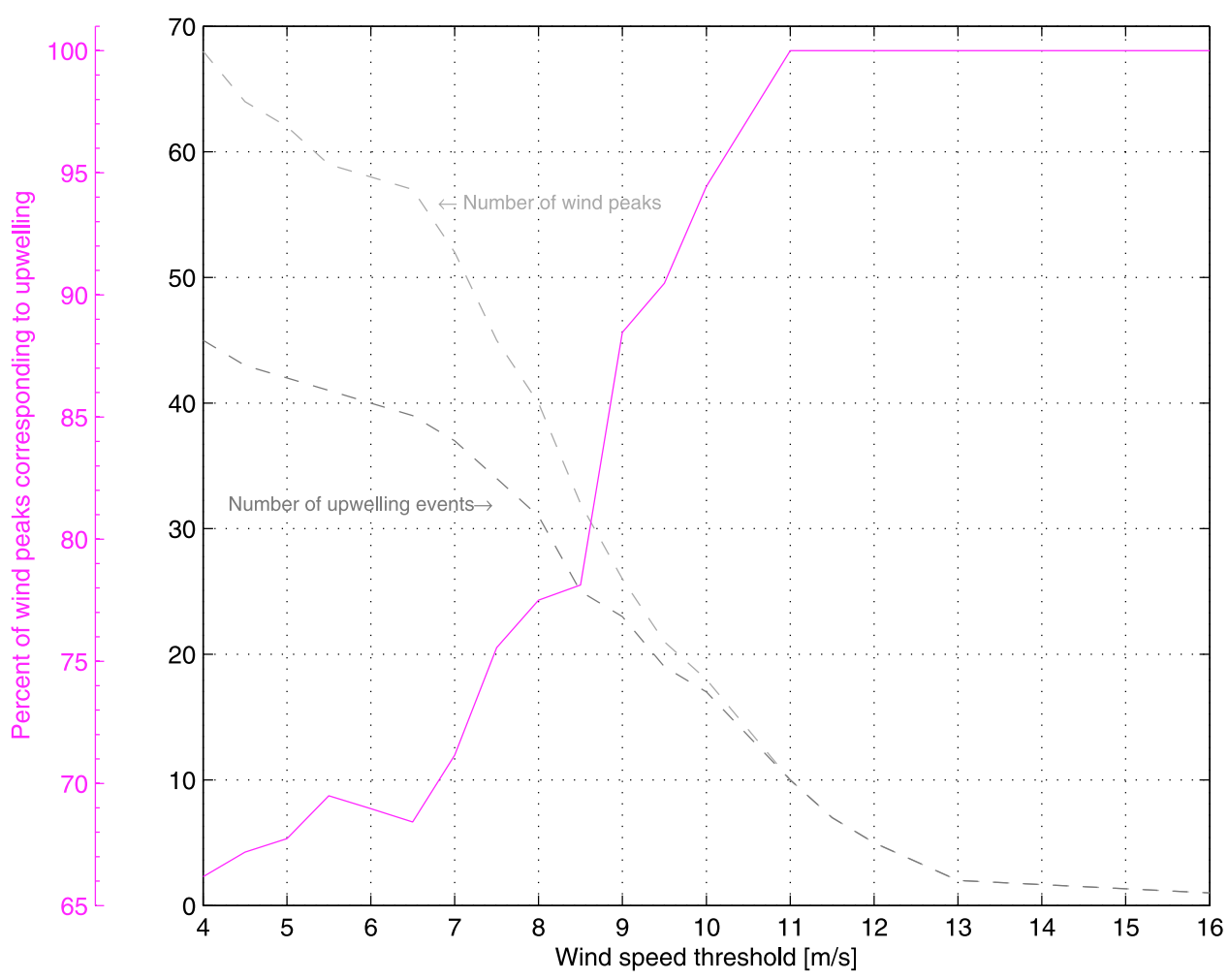

Figure 15. Percentage of storms that result in upwelling versus wind speed threshold (pink curve). The dashed lines show the number of wind peaks for the given wind speed threshold and the number of storms that resulted in upwelling. 


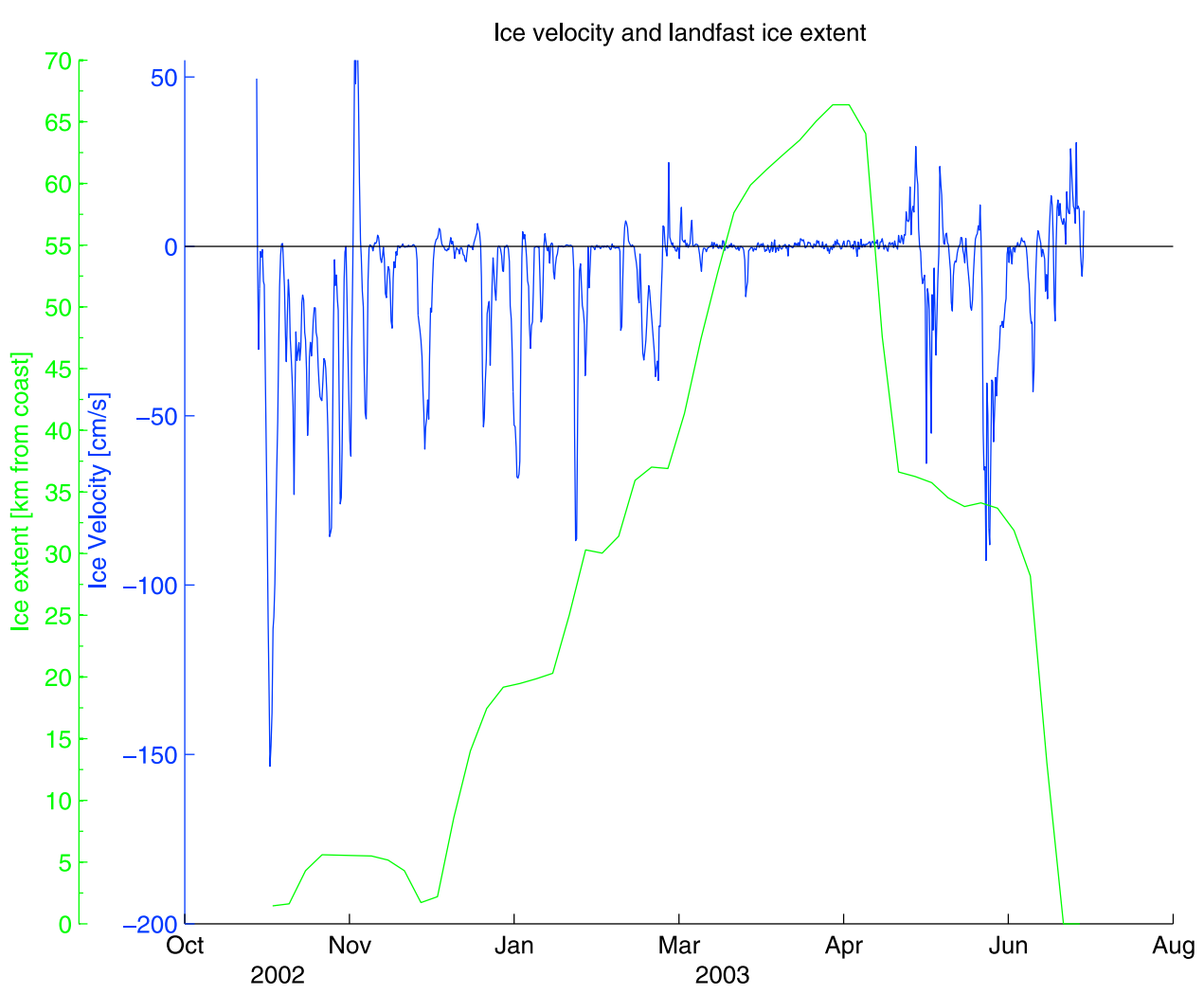

Figure 16. Ice velocity at the outer shelf (mooring BS2, blue curve) and landfast ice extent at this location along the Beaufort shelf (green curve). Mooring BS2 is located $55 \mathrm{~km}$ from the coast.

open water seasons. This is to be expected because internal ice stresses limit the transmission of wind stress in the full ice case. The information in Figure 15 is useful in that it will allow us to go back in time and assess the extent and variability of upwelling along the Beaufort slope using the full 65-year wind record at Pt. Barrow.

\subsection{Landfast Ice}

[39] Landfast ice is known to form every year along the inner Beaufort shelf. It usually extends to approximately the $20 \mathrm{~m}$ isobath (roughly $20 \mathrm{~km}$ offshore), where it grounds in the Stamukhi zone due to ridging [Reimnitz et al., 1978; Mahoney et al., 2007]. Since the shelf break is $\mathrm{O}(50 \mathrm{~km})$ offshore, it means that, under normal conditions, there is no landfast ice in the vicinity of the shelf edge. Using SAR imagery, however, Mahoney et al. [2007] revealed that there are times when fast ice can extend well offshore into the southern Beaufort Sea, to water depths as great as $3500 \mathrm{~m}$. Such episodes are referred to as "stable extensions," and Mahoney et al. [2007] found that these occurred most frequently during March and April in the Beaufort Sea.

[40] Using Mahoney et al.'s [2007] data for the time period of the SBI mooring array (see Section 2.3), we found that there were instances when the seaward limit of the landfast ice extended beyond mooring BS2, which was located roughly $55 \mathrm{~km}$ from the coast on the outer shelf. During the first deployment year this happened for an 8-week period from mid-March to mid-May (the green curve in Figure 16). This is verified using the ice velocity time series (blue curve in Figure 16) computed from the upward-facing ADCP at the base of the mooring (see section 2.2 and Pickart et al. [2009a] for a description of the method). One sees that there is excellent agreement between the two independent records (keep in mind that the time interval of the SAR data is 10 days, compared to the hourly ADCP ice velocity data).

[41] Does the presence of landfast ice over the shelf impact the upwelling response of the water column? Although there is no transfer of wind stress locally over the shelf and inner portion of the array during the seaward extension events, offshore of this the ice was mobile. This suggests that, while canonical coastal upwelling would not occur, the strong curl in the surface stress offshore of the shelf break would lead to divergence in the Ekman flow at that location and hence upwelling. Such ice-edge upwelling adjacent to immobile (or near immobile) ice has been observed [e.g., Buckley et al., 1979; Mundy et al., 2009] and modeled [e.g., Gammelsrod et al., 1975; Häkkinen, 1986] in various other geographical regions. We see evidence of it in our data as well. During the two-year deployment there were 8 upwelling events when immobile ice covered mooring BS2. Most of these were in April and March and in no instance did the landfast ice extend to the next mooring. Grossly speaking, seaward of the shelf break the response of the water column was similar to the mobile full-ice cases. That is, the shelf break jet reverses and salty water is brought to shallower depths along the continental slope. There is, however, a significant difference in the salinity anomaly composite for the landfast ice events versus that for the mobile full ice events (compare Figure 17 to Figure 6f). In particular, the salinity anomaly is more pronounced in the upper water column at the first mooring seaward of the landfast ice edge (mooring BS3). Also, there is a tongue of higher anomaly extending offshore at shallow 


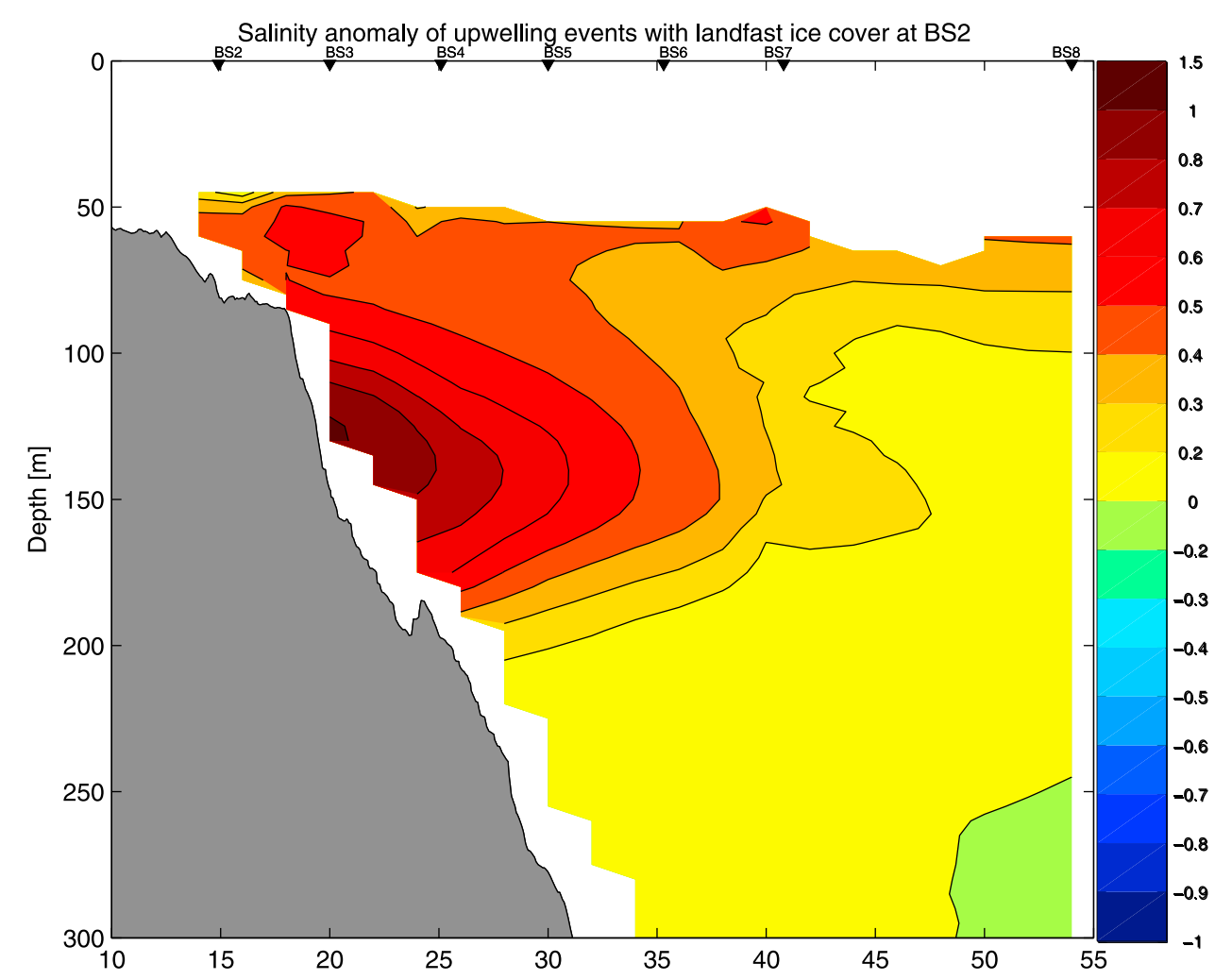

Figure 17. Composite salinity anomaly of the 8 landfast ice events. This is relative to the full-ice undisturbed composite (since the landfast events occurred during the full ice season).

depths, while onshore the anomaly is smaller. This is not the case when the ice is mobile everywhere, and suggests that salty water is brought more abruptly to the surface layer near mooring BS3 during the stable extension events - i.e., that ice edge upwelling is occurring.

[42] On the shelf (underneath the landfast ice) the response should be different as well. Kasper and Weingartner [2012] modeled the water column response to upwelling favorable winds under different configurations of landfast ice on a shelf. Their model set-up (motivated by the conditions in the Alaskan Beaufort Sea) consisted of a zonal coastline and gently sloping shelf to the north, where a region of the inner shelf was impermeable to wind stress. In the case when the seaward extent of this rigid lid did not vary along the shelf, a weak eastward (upwind) flow developed under the ice. This is due to the adjustment of the sea surface from the region of upwelling at the ice edge to the region near the coast (i.e., a negative sea surface slope with northward distance, opposite to that in the open water seaward of the ice). We observed no such eastward flow at mooring BS2 under the landfast ice. While the composite along-stream velocity was weaker than that for the mobile full-ice composite $\left(0-10 \mathrm{~cm} \mathrm{~s}^{-1}\right.$ versus $10-25 \mathrm{~cm} \mathrm{~s}^{-1}$, Figure 18a), it was without exception downwind. This is explainable, however, by an along-shelf variation in the landfast ice extent.

[43] Kasper and Weingartner [2012] also considered a case where the landfast ice was confined to the eastern part of the shelf; i.e., the rigid lid did not extend all the way to the western boundary. In this case the flow under the ice was westward (downwind). The reason for this is that the sea surface elevation drops substantially at the coast immediately west of the rigid lid, and this signal propagates eastward under the ice (along the coast) setting up a positive sea surface height gradient to the north. In this model scenario, the primary (along-shelf) flow is weaker near the rigid lid and near the bottom due to friction, while the corresponding secondary circulation is directed onshore both at the top and at the bottom, with weak offshore flow in the middle of the water column [Kasper, 2012].

[44] Using Mahoney et al.'s [2007] data derived from SAR imagery, we documented the along-stream variation in the seaward extent of the landfast ice edge during the 8 storms in question. In all cases the landfast ice extent decreased toward Pt. Barrow (there is usually minimal landfast ice in Barrow Canyon). Furthermore, roughly $50 \mathrm{~km}$ west of the array the ice edge underwent an excursion to the south in each instance (e.g., Figure 19), which is similar to the model scenario considered by Kasper and Weingartner [2012]. This westward trend in landfast ice was consistent with the satellite ice concentration data as well, indicating less ice cover to the west during these periods (not shown). This implies that our observations should be more in line with the partial rigid lid case studied by Kasper and Weingartner [2012]. This is indeed the case. The landfast ice composite along-stream velocity profile at mooring BS2 shows weaker flow near the surface and bottom (Figure 18a), while the secondary flow is directed onshore in these regions (Figure 18b), with weak offshore flow in between. This is in contrast to the case when the ice cover is full but mobile, where the along-stream flow is surface intensified and the cross-stream flow displays the two dimensional Ekman pattern discussed above. Note in Figure 19 that the mean vector at BS2 (under the landfast ice) 

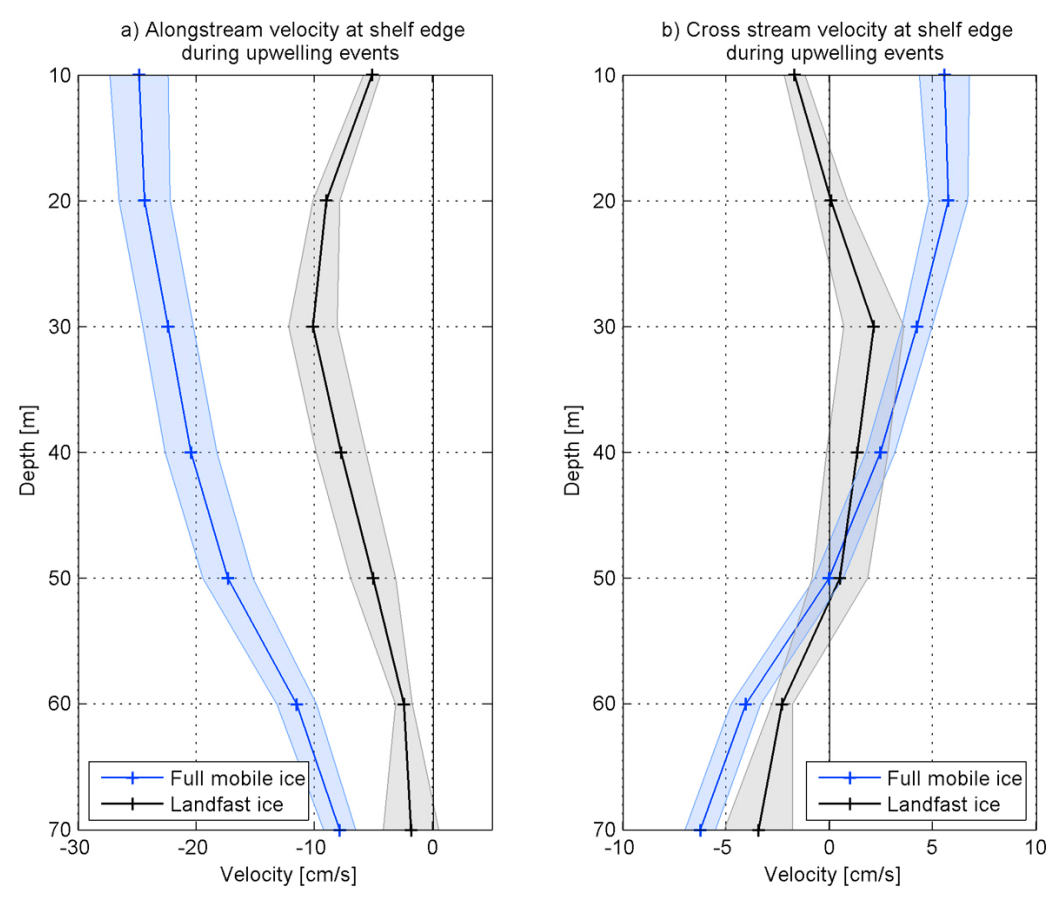

Figure 18. Composite velocity profiles at the edge of the shelf (mooring BS2) for storm events when there is full ice cover. The blue curves correspond to those events when the ice is mobile everywhere, and the black curves are for those events when the ice on the shelf is landfast: (a) along-stream velocity and (b) cross-stream velocity. The shading denotes the standard error.

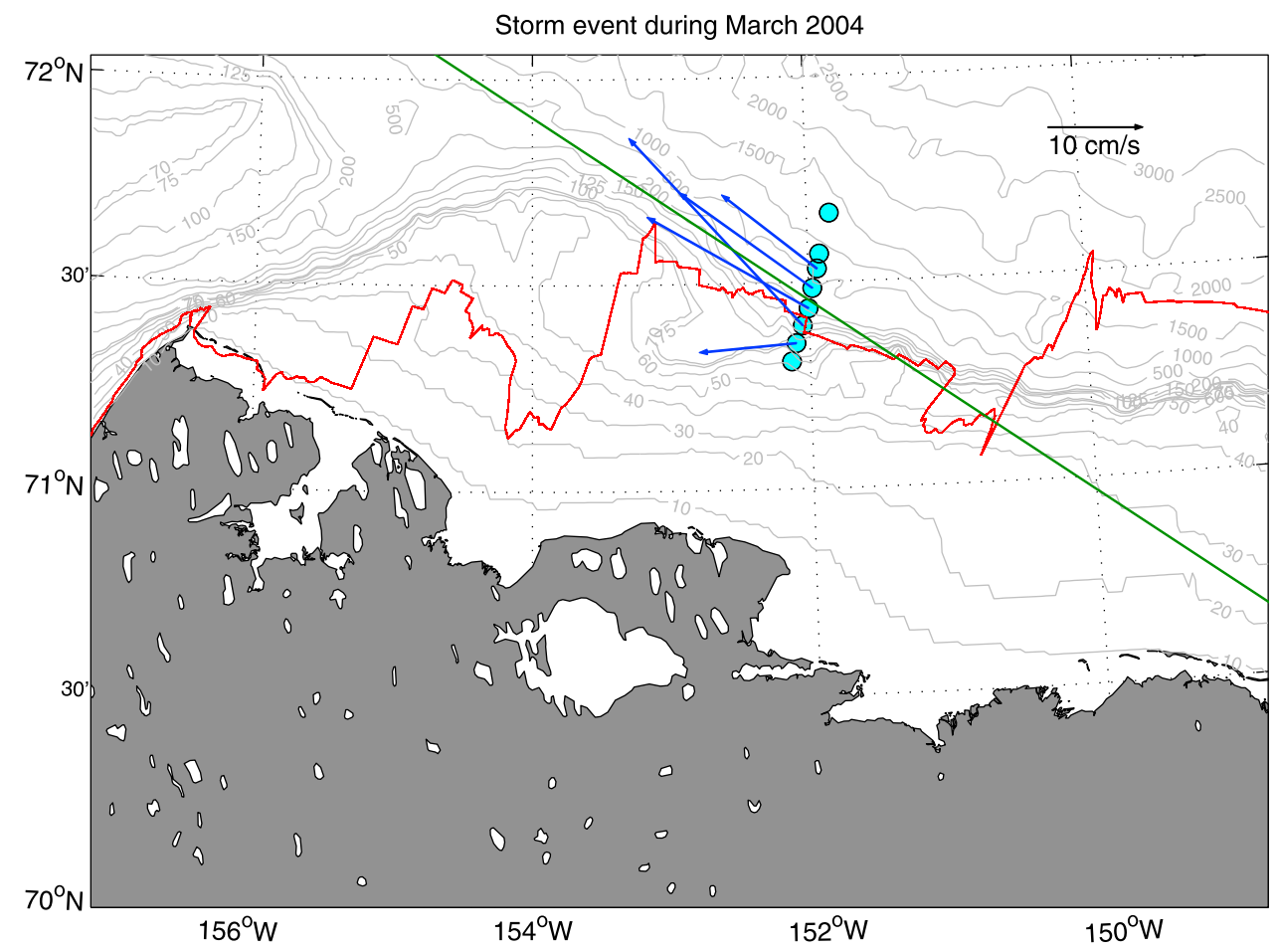

Figure 19. A storm event in March 2004 when there was landfast ice over the shelf. The landfast ice edge is plotted in red. The blue vectors show the average flow over the upper $100 \mathrm{~m}$ at moorings BS2-BS6, and the green line shows the overall average flow direction of the event. 
is weaker and directed more onshore during the storm. In general then, our results are consistent with the under-ice circulation pattern predicted by Kasper and Weingartner [2012] when there is less landfast ice to the west.

\section{Summary}

[45] We have shown that the water column response to upwelling favorable winds in the Alaskan Beaufort Sea differs significantly depending on the ice cover. The response is consistently strongest when there is partial ice cover present, likely due to the ability of freely moving ice keels to impart more stress into the water column for a given wind strength. During this relatively narrow time period in the fall (and presumably in the spring) the storms cause the shelf break jet to reverse more strongly to the west, a larger quantity of salt is advected upslope, and the secondary circulation is more intense. Accordingly, the upward isopycnal displacements along the slope are greater and the upwelling rates are stronger. In general, the water column response to easterly winds is weakest when the ice cover is near $100 \%$ (but remains mobile); however, since storms tend to last longer during this part of the winter the isopycnal displacements are comparable to the open water season.

[46] In all ice seasons - as long as the ice is mobile - the secondary circulation at the edge of the shelf represents an approximate two-dimensional Ekman cell, with offshore flow in the upper layer and a nearly equal amount of onshore flow at depth. Assuming a $500 \mathrm{~km}$ along-shelf length scale for the storms, this implies a cross-shelf exchange of $1.3 \mathrm{~Sv}$ on average. However, at times landfast ice can extend all the way to the shelf edge, which alters the upwelling response. In particular, ice-edge upwelling occurs seaward of the shelf break, and the primary and secondary circulation under the landfast ice changes: the along-stream flow is weaker-but still downwind - and the cross-stream flow no longer displays the same Ekman pattern at the edge of the shelf. Instead, the cross-stream flow is directed onshore near the surface and near the bottom, and weakly offshore in the middle of the water column. This pattern is consistent with previous modeling results when there is an along-shelf variation in the extent of the landfast ice, i.e., less landfast ice to the west as observed. An upwelling index was constructed, using empirical orthogonal functions, which allowed us to characterize the strength of the water column response with a single variable. The index was most influenced by the salinity and along-stream velocity, but was more effective at identifying upwelling events when constrained by the secondary flow time series as well. Using the wind record alone to predict upwelling is more than $90 \%$ accurate for storms in which the wind exceeds $9.5 \mathrm{~m} \mathrm{~s}^{-1}$, and $100 \%$ accurate for winds greater than $11 \mathrm{~m} \mathrm{~s}^{-1}$.

[47] Our results indicate that the wind-driven shelf-basin exchange in the western Arctic depends significantly on the ice cover. Since the seasonal ice cover in this region is changing so markedly due to the warming climate, this has important ramifications. Decades ago it was not uncommon for the Beaufort shelf and slope to remain ice covered throughout the year; that is, the full-ice cover scenario described above was applicable for most or all of the year. This implies that the upwelling response in the Beaufort Sea is intensifying, with concomitant increases in the offshore fluxes of freshwater and heat. This may help explain the recent increase in the freshwater content of the Beaufort Gyre [Proshutinsky et al., 2009] over the past decade, as well as the later freeze up that is occurring in the southern Canada Basin [Markus et al., 2009]. The enhanced on-shelf flux of nutrients from the Pacific Winter Water, in concert with the reduced ice cover in late summer (meaning greater penetration of light into the water column), may lead to increased primary productivity during the fall season. In addition to the decreasing ice concentration, the pack-ice has also been thinning in recent years [e.g., Hutchings and Rigor, 2012]. This in turn implies a more unstable pack-ice cover that could also lead to increased ice mobility and hence more instances of the maximum upwelling response described above. Finally, enhanced wind-forcing in a warming climate may amplify these effects further. This includes more storms [e.g., Zhang et al., 2004; Sorteberg and Walsh, 2008] as well as an intensification of the Beaufort High [e.g., Moore, 2012], both of which lead to more prominent easterly winds in this area of the Arctic. As such, upwelling in the Beaufort Sea may reach unprecedented levels in the coming years.

[48] Acknowledgments. The authors wish to thank Paula Fratantoni for assistance with identifying the upwelling events, Dan Torres for providing the ice velocity data, Andy Mahoney for sharing the Beaufort Sea landfast ice product, and Jeremy Kasper for helpful discussions. L.M.S. acknowledges the Year in Industry Program at the University of East Anglia. The following grants provided support for this study: National Ocean Partnership Program project N00014-07-1-1040 and National Science Foundation projects OPP-0731928 and OPP-0713250.

\section{References}

Aagaard, K., and A. T. Roach (1990), Arctic ocean-shelf exchange: Measurements in Barrow Canyon, J. Geophys. Res., 95, 18,163-18,175, doi:10.1029/JC095iC10p18163.

Barth, J. A., D. Bogucki, S. D. Pierce, and P. M. Kosro (1998), Secondary circulation associated with a shelf break front, Geophys. Res. Lett., 25, 2761-2764, doi:10.1029/98GL02104

Beardsley, R. C., D. C. Chapman, K. H. Brink, S. R. Ramp, and R. Schlitz (1985), The Nantucket Shoals Flux Experiment (NSFE79). Part 1: A basic description of the current and temperature variability, J. Phys. Oceanogr., 15, 713-748, doi:10.1175/1520-0485(1985)015<0713:TNSFEP $>2.0 . C O ; 2$.

Bourke, R. H., and R. G. Paquette (1976), Atlantic water on the Chukchi shelf, Geophys. Res. Lett., 3, 629-632, doi:10.1029/GL003i010p00629.

Buckley, J. R., T. Gammelsrød, J. A. Johannessen, O. M. Johannessen, and L. P. Røed (1979), Upwelling: Oceanic structure at the edge of the Arctic ice pack in winter, Science, 203(4376), 165-167, doi:10.1126/science. 203.4376.165

Carmack, E. C., and E. A. Kulikov (1998), Wind-forced upwelling and internal Kelvin wave generation in Mackenzie Canyon, Beaufort Sea, J. Geophys. Res., 96, 21,989-22,008.

Fratantoni, P. S., S. Zimmermann, R. S. Pickart, and M. Swartz (2006), Western Arctic Shelf- basin Interaction Experiment: Processing and calibration of moored profiler data form the Beaufort shelf-edge mooring array, Woods Hole Oceanogr. Inst. Tech. Rep. WHOI-2006-15, 34 pp., Woods Hole Oceanogr. Inst., Woods Hole, Mass.

Gammelsrod, T., M. Mork, and L. P. Roed (1975), Upwelling possibilities at an ice edge: A homogeneous model, Ma. Sci. Commun., 1(2), 115-145.

Grebmeier, J. M., L. W. Cooper, H. M. Feder, and B. I. Sirenko (2006), Ecosystem dynamics of the Pacific-influenced Northern Bering and Chukchi Seas in the Amerasian Arctic, Prog. Oceanogr., 71, 331-361, doi:10.1016/j.pocean.2006.10.001.

Häkkinen, S. (1986), Coupled ice-ocean dynamics in the marginal ice zones: Upwelling/downwelling and eddy generation, J. Geophys. Res., 91(C1), 819-832, doi:10.1029/JC091iC01p00819.

Hill, V., and G. Cota (2005), Spatial patterns of primary production on the shelf, slope and basin of the Western Arctic in 2002, Deep Sea Res., Part II, 52, 3344-3354, doi:10.1016/j.dsr2.2005.10.001.

Hutchings, J. K., and I. G. Rigor (2012), Role of ice dynamics in anomalous ice conditions in the Beaufort Sea during 2006 and 2007, J. Geophys. Res., 117, C00E04, doi:10.1029/2011JC007182. 
Kasper, J. L. (2012), Idealized modeling of circulation under landfast ice, $\mathrm{PhD}$ thesis, School of Fisheries and Ocean Sci., Univ. of Alaska Fairbanks, Fairbanks, Alaska.

Kasper, J. L., and T. J. Weingartner (2012), Modeling winter circulation under landfast ice: The interaction of winds with landfast ice, J. Geophys. Res., 117, C04006, doi:10.1029/2011JC007649.

Large, W. G., and S. Pond (1981), Open ocean momentum flux measurements in moderate to strong winds, J. Phys. Oceanogr., 11, 324-336, doi:10.1175/1520-0485(1981)011<0324:OOMFMI>2.0.CO;2.

Mahoney, A., H. Eicken, A. G. Gaylord, and L. Shaprio (2007), Alaska landfast sea ice: Links with bathymetry and atmospheric circulation, J. Geophys. Res., 112, C02001, doi:10.1029/2006JC003559.

Markus, T., J. C. Stroeve, and J. Miller (2009), Recent changes in Arctic sea ice melt onset, freezeup, and melt season length, J. Geophys. Res., 114 C12024, doi:10.1029/2009JC005436.

Mathis, J. T., R. S. Pickart, D. A. Hansell, D. Kadko, and N. R. Bates (2007), Eddy transport of organic carbon and nutrients from the Chukchi Shelf: Impact on the upper halocline of the western Arctic ocean, J. Geophys. Res., 112, C05011, doi:10.1029/2006JC003899.

Mathis, J. T., et al. (2012), Storm-induced upwelling of high $p \mathrm{CO}_{2}$ waters onto the continental shelf of the western Arctic Ocean and implications for carbonate mineral saturation states, Geophys. Res. Lett., 39, L07606, doi:10.1029/2012GL051574.

Moore, G. W. K. (2012), Decadal variability and a recent amplification of the summer Beaufort Sea High, Geophys. Res. Lett., 39, L10807, doi:10.1029/2012GL051570.

Mountain, D. G., L. K. Coachman, and K. Aagaard (1976), On the flow through Barrow Canyon, J. Phys. Oceanogr., 6, 461-470, doi:10.1175/ 1520-0485(1976)006<0461:OTFTBC $>2.0 . C O ; 2$.

Mundy, C. J., et al. (2009), Contribution of under-ice primary production to an ice-edge upwelling phytoplankton bloom in the Canadian Beaufort Sea, Geophys. Res. Lett., 36, L17601, doi:10.1029/2009GL038837.

Nikolopoulos, A., R. S. Pickart, P. S. Fratantoni, K. Shimada, D. J. Torres, and E. P. Jones (2009), The western Arctic boundary current at $152^{\circ} \mathrm{W}$ : Structure, variability, and transport, Deep Sea Res., Part II, 56 , 1164-1181, doi:10.1016/j.dsr2.2008.10.014.

Pickart, R. S. (2000), Bottom boundary layer structure and detachment in the shelf break jet of the Middle Atlantic Bight, J. Phys. Oceanogr., 30, 2668-2686, doi:10.1175/1520-0485(2001)031<2668:BBLSAD $>2.0$. $\mathrm{CO} ; 2$.

Pickart, R. S., and P. S. Fratantoni (2011), Wind-forced upwelling in Barrow Canyon: Transport of Pacific and Atlantic water masses, paper presented at the 11th AMS Conference on Polar Meteorology and Oceanography, Am. Meteorol. Soc., Boston, Mass.

Pickart, R. S., G. W. K. Moore, D. J. Torres, P. S. Fratantoni, R. A. Goldsmith, and J. Yang (2009a), Upwelling on the continental slope of the Alaskan Beaufort Sea: Storms, ice, and oceanographic response, J. Geophys. Res., 114, C00A13, doi:10.1029/2008JC005009.

Pickart, R. S., G. W. K. Moore, A. M. Macdonald, I. A. Renfrew, J. E. Walsh, and W. S. Kessler (2009b), Seasonal Evolution of Aleutian Low pressure System: Implications for the North Pacific Subpolar Circulation, J. Phys. Oceanogr., 39, 1317-1339, doi:10.1175/2008JPO3891.1.

Pickart, R. S., M. A. Spall, D. J. Torres, G. W. K. Moore, J. Mathis, and S. Moore (2010), Upwelling in the Alaskan Beaufort Sea: Forcing, dynamics, cross-stream fluxes, and biological implications, Eos Trans. $A G U, 91(26)$, Ocean Sci. Meet. Suppl., Abstract IT14C-07.

Pickart, R. S., M. A. Spall, G. W. K. Moore, T. J. Weingartner, R. A. Woodgate, K. Aagaard, and K. Shimada (2011), Upwelling in the Alaskan Beaufort Sea: Atmospheric forcing and local versus on-local response, Prog. Oceanogr., 88, 78-100, doi:10.1016/j.pocean.2010.11. 005

Pickart, R. S., M. A. Spall, L. M. Schulze, and G. W. K. Moore, (2012), Dynamics of wind-forced upwelling in the Alaskan Beaufort Sea and associated shelf-basin fluxes, paper presented at 2012 Ocean Sciences Meeting, AGU, Salt Lake City, Utah, 20-24 Feb.

Pite, H. D., D. R. Topham, and B. J. vanHardenberg (1995), Laboratory measurements of the drag forces on a family of two-dimensional ice keel models in a two-layer flow, J. Phys. Oceanogr., 25, 3008-3031, doi:10.1175/1520-0485(1995)025<3008:LMOTDF>2.0.CO;2.

Proshutinsky, A., R. Krishfield, M. L. Timmermans, J. Toole, E. Carmack, F. McLaughlin, W. J. Williams, S. Zimmermann, M. Itoh, and K. Shimada (2009), Beaufort Gyre freshwaterreservoir: State and variability from observations, J. Geophys. Res., 114, C00A10, doi:10.1029/ 2008JC005104.

Reimnitz, E., L. Toimil, and P. Barnes (1978), Arctic continental shelf morphology related to sea ice zonation, Beaufort Sea, Alaska, Mar. Geol., 28, 179-210, doi:10.1016/0025-3227(78)90018-X.

Shimada, K., T. Kamoshida, M. Itoh, S. Nishino, E. Carmack, F. McLaughlin, S. Zimmermann, and A. Proshutinsky (2006), Pacific Ocean inflow: Influence on catastrophic reduction of sea ice cover in the Arctic Ocean, Geophys. Res. Lett., 33, L08605, doi:10.1029/2005GL025624.

Sorteberg, A., and J. E. Walsh (2008), Seasonal cyclone variability at 70 degrees $\mathrm{N}$ and its impact on moisture transport into the Arctic, Tellus, Ser. A, 60, 570-586, doi:10.1111/j.1600-0870.2008.00314.x.

Spall, M. A., R. S. Pickart, P. S. Fratantoni, and A. J. Plueddemann (2008), Western arctic shelf break eddies: Formation and transport, J. Phys. Oceanogr., 38, 1644-1668, doi:10.1175/2007JPO3829.1.

Spreen, G., L. Kaleschke, and G. Heygster (2008), Sea ice remote sensing using AMSR-E $89 \mathrm{GHz}$ channels, J. Geophys. Res., 113, C02S03, doi:10.1029/2005JC003384.

Steele, M., J. Zhang, and W. Ermold (2010), Mechanisms of summertime upper Arctic Ocean warming and the effect on sea ice melt, J. Geophys. Res., 115, C11004, doi:10.1029/2009JC005849.

von Appen, W., and R. S. Pickart (2012), Two configurations of the western Arctic shelfbreak current in summer, J. Phys. Oceanogr., 42, 329-351, doi:10.1175/JPO-D-11-026.1.

Watanabe, E. (2011), Beaufort shelf break eddies and shelf-basin exchange of Pacific summer water in the western Arctic Ocean detected by satellite and modeling analyses, J. Geophys. Res., 116, C08034, doi:10.1029/ 2010JC006259.

Watanabe, E., and H. Hasumi (2009), Pacific water transport in the Western Arctic Ocean simulated by an eddy-resolving coupled sea ice-ocean model, J. Phys. Oceanogr., 39, 2194-2211, doi:10.1175/2009JPO4010.1.

Williams, W. J., E. C. Carmack, K. Shimada, H. Melling, K. Aagaard, R. W. Macdonald, and R. G. Ingram (2006), Joint effects of wind and ice motion in forcing upwelling in Mackenzie Trough, Beaufort Sea Cont. Shelf Res., 26, 2352-2366, doi:10.1016/j.csr.2006.06.012.

Yang, J. (2006), The seasonal variability of the Arctic ocean Ekman transport and its role in the mixed layer heat and salt fluxes, J. Clim., 19, 5366-5387, doi:10.1175/JCLI3892.1

Zhang, X., J. E. Walsh, J. Zhang, U. S. Bhatt, and M. Ikeda (2004), Climatology and interannual variability of Arctic cyclone activity: 1948-2002, J. Clim., 17, 2300-2317, doi:10.1175/1520-0442(2004)017<2300 $\mathrm{CAIVOA}>2.0 . \mathrm{CO} ; 2$

Zhang, J., M. Steele, and R. Woodgate (2008), The role of Pacific water in the dramatic retreat of Arctic sea ice during summer 2007, Adv. Polar Sci., 19, 93-107. 